\title{
Optimization of phenolic antioxidants extraction from Fucus vesiculosus by pressurized liquid extraction
}

Sumampouw, Giovanni Arneldi; Jacobsen, Charlotte; Getachew, Adane Tilahun

Published in:

Journal of Applied Phycology

Link to article, DOI:

10.1007/s10811-020-02362-3

Publication date:

2021

Document Version

Peer reviewed version

Link back to DTU Orbit

Citation (APA):

Sumampouw, G. A., Jacobsen, C., \& Getachew, A. T. (2021). Optimization of phenolic antioxidants extraction from Fucus vesiculosus by pressurized liquid extraction. Journal of Applied Phycology, 33, 1195-1207. https://doi.org/10.1007/s10811-020-02362-3

\section{General rights}

Copyright and moral rights for the publications made accessible in the public portal are retained by the authors and/or other copyright owners and it is a condition of accessing publications that users recognise and abide by the legal requirements associated with these rights.

- Users may download and print one copy of any publication from the public portal for the purpose of private study or research.

- You may not further distribute the material or use it for any profit-making activity or commercial gain

- You may freely distribute the URL identifying the publication in the public portal 
1 Optimization of phenolic antioxidants extraction from Fucus vesiculosus by pressurized

2 liquid extraction

3

4 Giovanni Arneldi Sumampouw, Charlotte Jacobsen, ${ }^{*}$, and Adane Tilahun Getachew

5

6 Research Group for Bioactives-Analysis and Application, National Food Institute, Technical

7 University of Denmark, 2800 Kongens Lyngby, Denmark

8

9 Corresponding author: Charlotte Jacobsen

10 Email: chja@,food.dtu.dk

11

12

13 


\section{Abstract}

15 This study aimed to optimize pressurized liquid extraction (PLE) of phenolic compounds from 16 brown seaweed Fucus vesiculosus to obtain extract with high yield, rich in phenolic compounds, 17 good radical scavenging and metal chelating ability. The extraction was optimized with Box18 Behnken design experiment and response surface tool. Optimal condition were found at $19137.18^{\circ} \mathrm{C}, 58.65 \% \mathrm{v} / \mathrm{v}$ ethanol in water and $4.68 \mathrm{~min}$ extraction time which resulted in yield of $2031.16 \%$ dry basis, total phenolic content (TPC) of $3.69 \mathrm{~g}$ gallic acid equivalent (100 g dry 21 seaweed $)^{-1}$, effective concentration for $50 \%$ inhibition (EC50) of DPPH radical $\left(92.6 \mu \mathrm{g} \mathrm{mL}^{-}\right.$

$\left.22{ }^{1}\right)$, ABTS radical $\left(2.35 \mathrm{mg} \mathrm{mL}^{-1}\right)$ and metal chelating $\left(1.10 \mathrm{mg} \mathrm{mL}^{-1}\right)$. The TPC value and 23 radical scavenging activity of PLE extract were insignificantly different from the one obtained 24 from conventional solvent extraction, which proved PLE advantages in terms of shorter time 25 and less solvent requirement. Gallic, protocatechuic and gentisic acids were identified in the 26 PLE extracts.

28 Keywords: Fucus vesiculosus; phenolic antioxidants; pressurized liquid extraction; 29 antioxidant activity 
31 Seaweeds are known to contain a lot of bioactive compounds such as proteins, lipids, pigments, 32 iodine, halogenated compounds and phenols (Holdt and Kraan 2011). These compounds can

33 be extracted for their functionalities in food or pharmaceutical products. One brown seaweed species that has a great potential is Fucus vesiculosus. Although there is no big scale cultivation and harvesting of this species recorded in Denmark, availability of this species is very high since it is the most common canopy forming species in the Baltic Sea (Wikström and Kautsky

37 2007). Harvesting of this species has been done exclusively at the Atlantic coast of Ireland and 38 France, while its cultivation is still in experimental stage (Meichssner et al. 2020). This species contains high amounts of phenolic compounds with antioxidant activity, with content varying from $<0.4-12.2 \%$ of dry weight gallic acid equivalent (GAE) (Holdt and Kraan 2011; Hermund et al. 2018; Ummat et al. 2020).

43 These phenolic compounds are possible alternatives for replacing synthetic antioxidants in 44 delaying lipid oxidation and prolonging food shelf life. They have been proven to be good antioxidants when applied in granola bars (Karadağ et al. 2017), cod mince and cod liver oilin-water emulsion (Jónsdóttir et al. 2016) and facial cream (Hermund et al. 2018). Phenolic

47 compounds in F. vesiculosus are accumulated in a membrane-bound cytoplasmic vesicles 48 called physodes on the surface cells (Jacobsen et al. 2019). Although these phenolic compounds 49 could be as potent as synthetic ones, they co-exist amongst other compounds which might not 50 be active in managing oxidation. Therefore, selective extraction of these phenolic compounds 51 is needed to obtain antioxidant compounds with high activity. Beside the selectivity, 52 maximizing antioxidant yield from the extraction is important for these antioxidants to be 53 economically viable for competition with synthetic antioxidants since natural antioxidants are 54 more expensive than the synthetic ones (Berdahl et al. 2010). 
56 Currently, main conventional technique used for extracting bioactive compounds from 57 seaweed is solvent extraction (SE), where seaweed is exposed to organic solvents (Joana Gil58 Chávez et al. 2013). This traditional method has low efficiency and needs large volumes of 59 environmentally unfriendly organic solvents (Saha et al. 2017). Pressurized liquid extraction 60 (PLE) is a novel extraction method that utilizes solvent in subcritical condition to change the 61 physical properties in order to be more favorable for recovering hydrophobic secondary metabolites from their matrix (Plaza and Marina 2019). In subcritical zone, London dispersion forces (induced dipole-induced dipole forces) becomes more favorable than hydrogen bonding and thus solvent turns less polar (Marcus 2018). Therefore, generally recognized as safe (GRAS) solvents that are considered as environmentally friendly, such as ethanol, can be used in PLE (Alvarez-Rivera et al. 2020).

PLE is also a faster process for extraction compared to traditional SE (Marcus 2018) due to the following reasons. High pressure used increases diffusivity of solvent and enables better penetration of solvent into matrix particles to reach the analytes (Teo et al. 2010). At higher temperature, surface tension becomes lower which improves sample wetting and creates larger contact area between solvent and sample matrix (Plaza and Turner 2017). Higher temperature used in PLE compared to SE also decreases cohesive forces between solute molecules and adhesive forces between solute and matrix molecules by lowering the requirement of activation energy to desorb (Teo et al. 2010). Utilizing a dual mixture of solvents also gives another advantage, where one solvent could act to improve analyte solubility, while the other could enhance the analyte desorption (Mustafa and Turner 2011). 
79 Until now, to the best of authors' knowledge there has been no publications on application of

80 PLE for extracting phenolic compounds from $F$. vesiculosus. Therefore, the objective of this 81 study is to investigate the effect of some PLE parameters, i.e. extraction time, temperature and

82 ratio of ethanol to water; on total phenolic compounds (TPC), dry matter yield, radical 83 scavenging activity (measured by diphenylpicrylhydrazyl/DPPH and 2,2'-azino-bis(384 ethylbenzothiazoline-6-sulfonic acid)/ABTS) and also metal chelating ability. Furthermore, the 85 extraction process was optimized using mathematical models obtained from response surface 86 methodology. Optimization was done to obtain maximum amount of phenolic compounds with 87 good antioxidant properties. The extracts obtained from optimized condition were compared 88 to those produced with SE. Lastly, phenolic acids in the extracts were identified.

\section{Materials and methods}

\section{$91 \quad$ Sample preparation}

92 Brown seaweed F. vesiculosus were harvested on May 2018 from Bellevue beach,

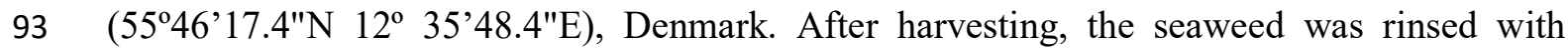
94 distilled water and its holdfasts and epiphytes were removed. The samples were frozen at $-20^{\circ} \mathrm{C}$ 95 prior to experiment. The seaweed was freeze dried in Christ Freeze Dryer Beta 1-8 (Osterode, 96 Germany) for 2 days and then powdered with CB15VXE Waring blender (Torrington, USA) 97 and sieved to remove large particles. The powdered seaweed was stored at $-20^{\circ} \mathrm{C}$ after being 98 purged with nitrogen to avoid oxidation.

\section{Pressurized Liquid Extractions}

\section{Single parameter effects screening}

102 The effects of extraction temperature $[\mathbf{T}]\left(75,100,125,150,175^{\circ} \mathrm{C}\right)$, extraction time $[\mathbf{t}](5,10$, $10315 \mathrm{~min})$ and ethanol concentration in solvent [E] $(40,60,80,100 \% \mathrm{v} / \mathrm{v}$ in water) on total 
phenolics content (TPC) were firstly investigated using single-factor experiment. Each parameter was optimized in triplicate experiments while other parameters were kept constant. Temperature range was chosen based on a study of PLE to extract phenolic compounds from another species of brown seaweed (Saccharina japonica) (Vo Dinh et al. 2018). This study concluded that maximum TPC was achieved at $125^{\circ} \mathrm{C}$. Ethanol concentration range was selected based on a PLE study on Sargassum muticum, a brown seaweed species (SánchezCamargo et al. 2016). The response surface experiment of this study gave $95 \%$ ethanol as optimum for extracting phenolic compounds. Extraction time range was picked between 5 and $15 \mathrm{~min}$ because the first study was operated at $5 \mathrm{~min}$, while the latter was run at $20 \mathrm{~min}$.

Experiment started by varying temperature and maintaining extraction time of 5 min and $80 \%$ $v / v$ ethanol. While performing extraction time variation, temperature and ethanol concentration were kept constant at $125^{\circ} \mathrm{C}$ and $80 \% v / v$ respectively. Lastly, temperature and time were maintained at $125^{\circ} \mathrm{C}$ and $5 \mathrm{~min}$ for ethanol concentration optimization. PLE was performed with Dionex ASE 350 Accelerated Solvent Extractor (Thermo Scientific, Leicestershire, UK). For each experiment, $1 \mathrm{~g}$ of dried seaweed powder and $1 \mathrm{~g}$ of Ottawa sand were mixed and loaded into a $10 \mathrm{~mL}$ extraction cell equipped with a cellulose filter on its bottom. Each experiment used maximum operating pressure of 10 bar, $50 \%$ rinsing volume and purge time of $100 \mathrm{~s}$. Samples were stored at $-20^{\circ} \mathrm{C}$ prior to characterization.

\section{Response surface for optimization}

A Box-Behnken factorial experimental design with three repetitions at the central point was used to observe the effect of each variable in single parameters screening experiments on yield, TPC and several antioxidant activities (DPPH, ABTS and metal chelating). Three levels of each variable were tested, and the values were set according to results of single parameter 
screening. A total of 15 different experiments (Table 1) were conducted in a randomized order. In this experiment, different configuration of seaweed and Ottawa sand was used to avoid filter blockage by seaweed swelling in presence of water, where $1 \mathrm{~g}$ of seaweed was sandwiched between $1.5 \mathrm{~g}$ of sand on the bottom and top of it without any mixing. JMP Pro 15 statistical software (SAS, Cary, USA) was used for analysis of variance (ANOVA) and response surface modelling with second-order polynomial equations. Model adequacy was evaluated using the coefficient of determination $\left(\mathrm{R}^{2}\right)$ and lack-of-fit test with a 5\% level of significance. Regression coefficients were generated with method of least squares to produce lowest possible residual. Optimization was done with top $\mathrm{N}$ pareto front search add-in in JMP with objectives of maximum TPC, DPPH and metal chelating ability. Fifty-one random sets of condition around the optimum for each antioxidant characteristic were generated by JMP and selection of the most optimum condition was done with helps of scatter plot, mixture plot and parallel plot.

\section{Models validation and comparison with conventional solvent extraction}

Validation of the optimum condition was done by conducting triplicate PLE experiments. As a comparison, conventional solvent extractions were also done in triplicate. Two kinds of solvents were used for this extraction, i.e. $80 \% v / v$ ethanol in water solution (best solvent for extracting antioxidants (Wang et al. 2012)) and ethanol solution with the same concentration as optimum PLE.

One gram of dried seaweed was submerged with $25 \mathrm{~mL}$ of solvent and incubated for $24 \mathrm{~h}$ at dark condition and room temperature on a shaker board (Heidolph Unimax 2010, Schwabach, Germany) with speed of $150 \mathrm{rpm}$. Afterwards, the mixture was centrifuged (Sartorius Sigma 4K15, Göttingen, Germany) at $2900 \times g$ for $10 \mathrm{~min}$. The residue was re-extracted under the same condition as above. The supernatant of re-extraction was mixed with supernatant from the day 
154

155

156

157

158

159

160

161

162

163

164

165

166

167

168

169

170

171

172

173

174

175

176

before reaching total volume of $50 \mathrm{~mL}$. Lastly, the mixture of supernatants was filtered with Whatman filter no. 4. Both extracts from validation and conventional solvent extraction were analyzed with the same assays as response surface experiments.

\section{Extraction yield}

Five $\mathrm{mL}$ of each extracted samples were weighed and then evaporated with nitrogen gas purging. The solution was dried further in a freeze dryer (Christ Freeze Dryer Beta 1-8, Osterode, Germany) for 1 day after being frozen in a $-20^{\circ} \mathrm{C}$ freezer. The powder products were weighed again, and those data were used for yield calculation on dry matter basis.

\section{Total phenolic compounds (TPC)}

TPC was determined with Folic-Ciocalteu assay based on method from Farvin and Jacobsen (Sabeena Farvin and Jacobsen 2013). $100 \mu \mathrm{l}$ of diluted extract was mixed with $750 \mu \mathrm{L}$ of FolinCiocalteu reagent $(10 \% v / v$ in water) in a plastic microcuvette. The mixture was incubated for 5 min and then $750 \mu \mathrm{L}$ of sodium carbonate $\left(\mathrm{Na}_{2} \mathrm{CO}_{3}, 7.5 \% w / v\right.$ in water $)$ was added. This mixture was incubated at room temperature in dark condition for 90 min more. Afterwards, absorbance of this mixture was measured at $725 \mathrm{~nm}$ using a spectrophotometer (Shimadzu UV mini 1240, Duisburg, Germany). TPC value of each extract was measured in triplicate and reported as mean with standard deviation of all measurements. Amount of total phenolics were calculated as milligrams of gallic acid equivalents (mg GAE) per $100 \mathrm{~g}$ of dry seaweed based on a standard curve for gallic acid solution with concentrations from $7.8125 \mu \mathrm{g} \mathrm{mL}^{-1}$ to $250 \mu \mathrm{g}$ $\mathrm{mL}^{-1}$. 


\section{DPPH radical capacity scavenging}

178 Method for the assay was adopted from Hermund et al. (Hermund et al. 2018). An aliquot (100

$179 \mu \mathrm{L}$ ) of extract at a concentration of $0.5 \mathrm{mg} \mathrm{mL}^{-1}$ were poured into a well in a microtiter plate.

$180100 \mu \mathrm{L}$ of DPPH $(0.1 \mathrm{mM}$ in ethanol) was added to each well. These mixtures were incubated

181 for $30 \mathrm{~min}$ at room temperature in dark condition Afterwards, absorbance of each mixture was 182 measured at wavelength of $517 \mathrm{~nm}$ in a BioTek Eon Microplate Spectrophotometer (Bad 183 Friedrichshall, Germany). Effective concentrations for 50\% inhibition (EC50) were calculated 184 with Origin 2019b software (Northampton, USA) using dose-response model.

\section{ABTS radical capacity scavenging}

ABTS assay was done using modified protocol from Stengel and Connan (Stengel and Connan 2015). $10 \mathrm{~mL}$ of ABTS solution $(7 \mathrm{mM})$ was mixed with $10 \mathrm{~mL}$ of potassium persulfate $(2.45$ $\mathrm{mM}$ ) and incubated at $4^{\circ} \mathrm{C}$ for $24 \mathrm{~h}$ to form $\mathrm{ABTS}^{+}$radical. This solution was diluted once more with ethanol until reaching absorbance of $0.7 \pm 0.02 \mathrm{AU}$ at $734 \mathrm{~nm} .990 \mu \mathrm{L}$ of this solution was poured into a $1.5 \mathrm{~mL}$ plastic Eppendorf tube and mixed with $10 \mu \mathrm{L}$ of extract sample at concentration of $0.5 \mathrm{mg} \mathrm{mL}^{-1}$. The mixture was vortexed and incubated for $6 \mathrm{~min}$ at $30^{\circ} \mathrm{C}$ and dark condition. The absorbance of each sample was measured with BioTek Eon Microplate Spectrophotometer (Bad Friedrichshall, Germany) at $734 \mathrm{~nm}$ by pipetting $200 \mu \mathrm{L}$ of each solution into a well in a microtiter plate. All experiments were done in triplicate. EC50 values were calculated with Origin 2019b software (Northampton, USA) using dose-response model.

\section{Metal chelating capacity}

200 The method for measuring metal chelating ability was based on Hermund et al. (Hermund et al. 2018). In brief, $100 \mu \mathrm{L}$ of antioxidant extracts with concentration of $1.5 \mathrm{mg} \mathrm{mL}^{-1}$ were 
pipetted into a well of a microtiter plate. $110 \mu \mathrm{L}$ distilled water and $20 \mu \mathrm{L}$ ferrous chloride solution $(0.5 \mathrm{mM})$ were mixed into the samples. After 3 min of incubation, $20 \mu \mathrm{L}$ ferrozine solution $(2.5 \mathrm{mM})$ was added into each well. The plate was kept in dark for 10 min of incubation at room temperature. The absorbance of each solution was measured at $562 \mathrm{~nm}$ in a BioTek Eon Microplate Spectrophotometer (Bad Friedrichshall, Germany). Effective concentrations for $50 \%$ chelating activity (EC50) were calculated with Origin $2019 \mathrm{~b}$ software (Northampton, USA) using dose-response model.

\section{Phenolic acid identification}

Method for phenolic acid identification was modified from Farvin and Jacobsen (Sabeena Farvin and Jacobsen 2013). The extracts from model validation and conventional solvent extraction were passed through a PVDF type syringe filter $0.22 \mu \mathrm{m}$ before being injected into HPLC at a concentration of $9 \mathrm{mg} / \mathrm{mL}$. The column used for this purpose was Prodigy $5 \mu \mathrm{m}$ ODS-3 $100 \AA \AA$. The equipment consisted of an Agilent 1100 series HPLC (Agilent Technologies, Waldbronn, Germany) and a diode array detector (Agilent G1315A).

Two types of mobile phases were used for this analysis: phosphoric acid in deionized water with $\mathrm{pH}$ value of $3(\mathrm{~A})$, and 1:1 mixture of methanol and acetonitrile (B). The gradient elution analysis program was as follows: $0-2 \mathrm{~min}, 5 \%$ (B); $2-20 \mathrm{~min}$, increasing to $40 \%$ (B); $20-35$ min, increasing to $100 \%(\mathrm{~B}) ; 35-37 \mathrm{~min}$, decreasing to $5 \%(\mathrm{~B})$, with $3 \mathrm{~min}$ of posttime at a flow rate of $0.9 \mathrm{~mL} \mathrm{~min}^{-1}$. Injection volume of sample was set at $20 \mu \mathrm{L}$ and the column was maintained at $25^{\circ} \mathrm{C}$. Detection with the diode array detector was done at four different wavelenghts, i.e. $235,255,280$ and $325 \mathrm{~nm}$ with reference wavelenght of $360 \mathrm{~nm}$. Quantification and identification of each phenolic acid was done by producing calibration curve by injecting phenolic acids mixture standards with concentration of each phenolic acid 
227 (gallic, caffeic, chlorogenic, gentisic, vanillic and protocatechuic acid) from 5.21 to $166.67 \mu \mathrm{g}$

$228 \mathrm{~mL}^{-1}$.

229

230

Table 1

231

232 Results

233 Single parameter effects on TPC

234 Effect of each single parameter effect on TPC value of extract is shown in Fig. 1. The shortest 235 extraction time which was 5 min gave significantly higher TPC (2.82 $\pm 0.1 \mathrm{~g}$ GAE (100 g dry 236 seaweed $\left.)^{-1}\right)$ than 10 and $15 \min (p<0.05)$. Furthermore, TPC value reached maximum at 100 237 and $125^{\circ} \mathrm{C}$ with significantly lower values at higher and lower temperature points tested $(p<$ 238 0.05). When ethanol concentration in solvent was varied, the significant highest phenolic 239

Fig. 1

243

244 These results of single parameter effects were utilized to define levels of each parameter in 245 experimental design. For temperature, optimization around $125^{\circ} \mathrm{C}$ was done with narrower 246 range from 110 to $140^{\circ} \mathrm{C}$. Extraction time less than 5 min was investigated for a hypothesis of 247 giving higher TPC value due to less phenolic compounds degradation. Therefore, time 248 optimization was done between 3 and 7 min. Range for ethanol concentration chosen was 249 between 40 to $80 \% v / v$ because antioxidant activity on these points should be inspected 250 although the TPC values were high. The assigned experimental design for response surface 251 experiments are shown in Table 1. 
253 Response surface model results

254 Experimental results of extraction yield and antioxidant properties using Box-Behnken design

255

256

257

258

259

260

261

262

263

264

265

266

267

268

269

270

271

272

273

274

275

276

277

are shown in Table 1. Analysis of variance (ANOVA) was done to screen the significance of each independent variable and their derivations for overall models built as shown in Table S.1. The models were refitted without statistically insignificant effects to obtain more precise estimate of the model parameters. Extraction time was not significant, but still be included in the model to be optimized. The developed mathematical models for predicting extraction yield and each antioxidant property are shown in Equation (1) through (5). These models were used to predict each parameter value and the results were compared with actual experimental data (Table S.2). Little differences were found between them which showed the adequacy of the models. ANOVA test for each equation (Table S.3) proved that all models were statistically significant with $p$-values lower than 0.05 . On the other hand, $p$-values of lack of fit in each model were higher than 0.05 which showed that lack of fit, relative to pure error, were not significant.

$$
\begin{aligned}
& \text { Yield }(\%)=-236.8104+4.8423 E+1.4988 T+0.5187 t-0.0188 E^{2}-0.0209 E . T \\
& T P C=-39.3426+0.8207 E+0.2542 T+0.0175 t-0.0028 E^{2}-0.0037 E . T \\
& D P P H=113.7723-0.3457 E-0.2125 T-0.0563 t+0.0018 E^{2}-0.0022 E . T \\
& \text { ABTS }=65.8006-0.1324 E-0.5158 T-0.725 t-0.0052 E^{2}+0.0066 E . T \\
& F^{2+} \text { Chelating Ability }=366.6935-4.9714 E-2.4633 T-0.7125 t-0.0020 E^{2} \\
& +0.0382 \text { E.T }
\end{aligned}
$$

Fig. 2 presents response surface results of the effect of extraction temperature, time and ethanol concentration in solvent on extraction yield, TPC value, DPPH inhibition activity, ABTS inhibition activity and metal chelating activity. Fig. 2 a and b shows that highest extraction 
278 yield could be achieved by higher extraction temperature and lower ethanol concentration. As 279 shown in three-dimensional response surface graphs in Fig. 2 c and d, high temperature and 280 low ethanolic solution were preferred to obtain highest TPC, which was similar to findings for 281 yield. Interaction between temperature and ethanol concentration was observed here, where 282 increasing temperature on low ethanol concentration can raise TPC value, while increasing 283 temperature on high ethanol concentration will reduce TPC value.

Maximum DPPH activity of phenolic compounds in extracts can be achieved when higher ethanol concentration and lower temperature were applied to the seaweed powder (see Fig. 2 e and f). These graphs also show that extract with high TPC value did not possess good DPPH negative effect on the ABTS inhibition activity as shown in Fig. $2 \mathrm{~g}$ and h. On the other hand, Fig. $2 \mathrm{i}$ and $\mathrm{j}$ depicts that highest activity of metal chelating could be accomplished with lower temperature and lower ethanol concentration. However, extract with high TPC value or DPPH scavenging activity was not a good metal chelating agent.

\section{Optimization}

Based on the mathematical models for each parameter, 51 combinations of temperature, extraction time and ethanol concentration which gave near-maximum value of each parameter were generated (Table S.4). Four potential solutions were chosen from these combination sets with the aid of mixture plots and a parallel plot (Fig. S.1, Fig S.2 and Fig. S.3). These four potential sets were then plotted in a scatter plot together with other solution sets as shown in 
303 Fig. 3, while the independent variables, predicted values of antioxidant properties and 304 desirability of all these potential solutions were listed in Table 2. In this study, objectives of optimization were maximum values of TPC, DPPH and metal chelating ability. Yield were not considered on the optimization since it had the same profile as TPC, while ABTS radical scavenging activity could be represented by DPPH. As the aim for this study was to extract maximum amount of phenolic compounds, optimization was more emphasized on TPC than other antioxidant properties.

Fig. 3

Table 2

The first potential solution (colored pink in Fig. 3) had the highest TPC value, but DPPH value of this solution was one of the lowest and the metal chelating ability was also quite low with desirability of 0.52 . The second potential solution (blue dot in Fig. 3) possessed one of the highest DPPH scavenging ability, but it was extract with the lowest metal chelating ability and intermediate TPC value. The third potential solution which was indicated by green dot in Fig. 3 achieved the highest total desirability among them. It owned one of the highest metal chelating capability and moderate DPPH inhibition value. This extract contained nonetheless one of the lowest phenolic compounds with desirability value of 0.59 . The last potential solution which colored in orange was one of the extracts with highest extraction yield of phenolic compound. Metal chelating ability of this extract was in average value, but the antioxidant capability of scavenging DPPH radical was one of the lowest with desirability value of 0.31. However, the DPPH inhibition percentage range of all combination sets was quite narrow. The DPPH inhibition activity of this last combination was $87.57 \%$ which indicated 
good antioxidant radical scavenging ability, and together with high value of TPC and moderate value of metal chelating ability, this solution was chosen for the optimized condition. Therefore, optimized PLE conditions was found to be temperature of $137.18^{\circ} \mathrm{C}$, ethanol concentration of $58.65 \% \mathrm{v} / \mathrm{v}$ and extraction time of $4.68 \mathrm{~min}$.

\section{Models validation and comparison with $\mathrm{SE}$}

Optimized condition was validated by performing triplicate experiments whose results were represented in Table 3, as well as comparison with the predicted value from the models. The validation suggested that the mathematical models produced were quite accurate and robust to predict all antioxidant properties with little error. The results of comparison of the this optimized PLE condition with SE were shown in Table 4. In comparison, SE with the same ethanol concentration as PLE yielded nearly the same amount of extract as the PLE process and gave nearly the same TPC value $(p>0.05)$. Meanwhile, SE with $80 \%$ ethanol resulted in lower phenolic content and powder yield compared to the two previously aforementioned extraction methods. For DPPH and ABTS radical scavenging ability, EC50 values of PLE were higher than SE with the same ethanol concentration. This finding means that more antioxidant extract obtained with PLE was needed to achieve the same activity as SE with optimized ethanol concentration extract. Moreover, in terms of metal chelating ability, SE extract with optimized ethanol concentration was found as a worse metal chelator than the one extracted using $80 \%$ ethanol as observed in the EC50 value. Extraction with pressurized liquid was also found to lower the metal chelating ability compared to SE.

\section{Table 3}

Table 4 
Phenolic acid identification

356

357

Identification of phenolic acid was done for six phenolic acid compounds which were reported in previous study to exist in F. vesiculosus (Sabeena Farvin and Jacobsen 2013). The quantification results for different extraction method and solvent are shown in Fig. 4 . Chlorogenic, vanillic and caffeic acids were not detected in all samples. More gallic acid was extracted using SE with 58.65\% ethanol $\left(335.1 \pm 14.4 \mu \mathrm{g}(\mathrm{g} \mathrm{DW})^{-1}\right)$ compared to PLE with the same ethanol concentration and SE with $80 \%$ ethanol.

\section{Fig. 3}

\section{Discussion}

F. vesiculosus as a brown seaweed species contains polyphenolic compounds, dominantly in the form of phlorotannins (polymer of phloroglucinol) (Wang et al. 2012). Phenolic compounds in polymer forms are more prone to degradation (De Paepe et al. 2014). These polyphenol compounds could degrade into soluble compounds and reversibly bonded phenolic were broken because of protein precipitation (Pangestuti et al. 2019). Therefore, high temperature might decrease TPC value due to degradation of these phlorotannins compounds as shown in Fig. 1 where TPC decreased after reaching highest value at 100 and $125^{\circ} \mathrm{C}$. However, the optimum temperature obtained for phenolic extraction in this study was a value high enough to enhance extraction yield but low enough to prevent degradation of the phenolic compounds (Catarino et al. 2019). Meanwhile, ethanol in a concentration of $40 \% v / v$ performed better for phenolic extraction with PLE which was different from SE. In SE, pure water is better for phenolic extraction compared to $80 \%$ ethanol in water (Koivikko et al. 2005). Solvent physical 
properties change a lot in subcritical condition, and the properties of $60 \%$ ethanol which gave maximum result might be similar to the best solvent for SE, which was $70 \%$ acetone in water (Koivikko et al. 2005).

The profile of obtaining higher yield by applying higher PLE temperature and lower ethanol concentration was also observed by several studies on PLE extraction of phenolic compounds from olive pomace (Pavez et al. 2019), goji berry (Tripodo et al. 2018) and jabuticaba skin (Santos et al. 2012). High temperature can enhance yield by improving wetting of sample matrix, disrupting analyte-matrix interactions and boosting diffusivity. However, the high yield on high temperature might also show co-extraction of some undesired compounds with the phenolic compounds (Plaza and Turner 2017). For obtaining highest TPC, the same condition for highest yield was preferred. Interaction between extraction temperature and ethanol concentration found in this study was also discovered by another study on PLE of flavonoid from spinach (Howard and Pandjaitan 2008). They examined that TPC linearly increased in ethanolic extracts over the temperature range of 90 to $170^{\circ} \mathrm{C}$, and then declined from 170 to $190^{\circ} \mathrm{C}$. In water extracts, TPC kept increasing linearly over the temperature range of 110 to $190^{\circ} \mathrm{C}$. Extraction time was not a significant parameter for TPC as also observed by Luthria (Luthria 2012).

In terms of DPPH radical scavenging activity, higher ethanol concentration and lower temperature were better to gain higher activity. The similar effect of ethanol concentration was discovered while extracting phenolic compounds from beetroot leaves where ethanol/water mixture gave less antioxidant reducing capacity than pure ethanol solvent (Battistella Lasta et al. 2019). Reducing DPPH activity trend when escalating temperature was also observed on another extraction experiment from walnut seed (Kamali et al. 2018). This profile can be 
explained by lower selectivity of extraction in higher temperature at temperature range of 110 $140^{\circ} \mathrm{C}$ and lower ethanol concentration in solvent. Although TPC value for these extracts were high, water in the solvent and high temperature enabled co-extraction of some water-soluble compounds from the sample matrix due to higher diffusivity of these contaminant compounds and increasing polarity of solvent. Amarante et. al. found out that phlorotannin amount in $F$. vesiculosus extracts obtained with microwave-assisted extraction with high temperature was lower than the ones collected from conventional extraction at room temperature (Amarante et al. 2020). They suggested that some lipophilic compounds such as fatty acids, sterols and fucoxanthin pigments were co-extracted at high temperature.

TPC assay might also detect other compounds than phenolic that have reducing capabilities (Jacobsen et al. 2019) such as laminarin (Olatunji 2020; Yugay et al. 2020) and fucoidan (Yugay et al. 2020). Laminarin and fucoidan capability of inhibiting DPPH radical was found to be lower than phenolic compounds extracted here, with inhibition of $1.09 \%$ for laminarin and $66.13 \%$ for fucoidan at a concentration of $1 \mathrm{mg} / \mathrm{mL}$ (Moroney et al. 2015). Although some simple sugars and ascorbic acid might also be co-extracted into the extracts, these compounds were proven to be unable to significantly interfere Folin-Ciocalteu causing overestimation of TPC values (Castro-Alves and Cordenunsi 2015).

When Ferreira et al. (Ferreira et al. 2019) extracted bioactive compounds from F. vesiculosus using SE with water as solvent, they also observed lower antioxidant ABTS inhibition for hotwater extracts which might be caused by phlorotannin degradation because of high temperature. ABTS cation is able to react with both lipophilic and hydrophilic antioxidant because it is soluble in aqueous and organic solvents (Stengel and Connan 2015). This fact often makes its activity higher than DPPH. However, ABTS inhibition activities in this study were always 
428 lower than the DPPH ones for the same extract (Table 1). This phenomenon was also noticed 429 for fucose-containing sulphated polysaccharides extracts from $F$. vesiculosus with higher 430 difference of ABTS and DPPH scavenging activity on extracts with higher TPC value (Imbs et

431 al. 2014). The possible reason for this could be antioxidant compounds in the extracts were not 432 very reactive towards ABTS radical cation or not enough time for complete reaction during the 433 incubation time (Ilyasov et al. 2020).

435 Water extract of $F$. vesiculosus was previously demonstrated to possess higher metal chelating 436 ability than ethanolic extract (Sabeena Farvin and Jacobsen 2013; Hermund et al. 2018). This 437 profile might indicate that phenolic compounds were not the major contributors to the metal 438 chelating properties (Wang et al. 2012; Sabeena Farvin and Jacobsen 2013). Hence, metal 439 chelating abilities of the extracts produced in this study might come from co-extracted 440 compounds in low ethanolic solvent. A good metal chelator forms $\sigma$-bonds with metal which 441 can reduce redox potential and thereby stabilizing the complex formed, and usually they are 442 indicated by functional groups such as $-\mathrm{OH},-\mathrm{SH},-\mathrm{COOH},-\mathrm{PO}_{3} \mathrm{H}_{2}, \mathrm{C}=\mathrm{O},-\mathrm{NR}_{2},-\mathrm{S}-$ and 443 O-(Yuan et al. 2005; Terpinc et al. 2012). Most of the phenolic compounds have only hydroxyl 444 groups among these potential functional groups which explains the low metal chelating ability.

446 The equations generated to predict the values of extraction yield, TPC, DPPH and ABTS 447 radical scavenging activities at $0.5 \mathrm{mg} \mathrm{mL}^{-1}$, and metal chelating ability at $1.5 \mathrm{mg} \mathrm{mL}^{-1}$ were 448 proven by validation experiments to be quite accurate with little error. These errors might come 449 because of the models' uncertainty as well as equipment limitation where decimal values could 450 not be inputted, consequently extractions were done at temperature of $137^{\circ} \mathrm{C}$ and time of $5 \mathrm{~min}$. 
452 The extraction yield of the optimized PLE condition was higher than polyphenols yield of PLE 453 from Fucus spiralis using 80\% ethanol in water (23.67\% dry weight) (Tierney et al. 2013).

454 This discrepancy might come from the different composition between different species and 455 lower temperature that they used $\left(100^{\circ} \mathrm{C}\right)$. The amount of water in the solvent used in this study 456 was also higher, which enabled co-extraction of some water-soluble compounds. This fact 457 shows the superiority of PLE compared to SE because the latter required longer extraction time 458 (48 h compared to $5 \mathrm{~min}$ for PLE) and higher solvent requirement (solvent to solid ratio of 50 $459 \mathrm{~mL}: 1 \mathrm{~g}$ compared to $17 \mathrm{~mL}: 1 \mathrm{~g}$ for PLE). Even though PLE requires energy to heat and 460 pressurize the system, SE also requires energy to agitate the mixture for a long time. The fact 461 that SE with lower ethanol concentration could produce more extract than the higher one was 462 also observed in other macroalgae (Monteiro et al. 2020).

Phenolic content of the SE extract with $80 \%$ ethanol was lower than the value reported for 465 polyphenols extraction from $F$. vesiculosus harvested from the same place and the same 466 extraction method as this study (16.5 g GAE/100 g) (Hermund et al. 2018). This can be 467 explained by the difference of harvesting month, where this study used seaweed harvested in May whereas the former harvested in September. TPC value of $F$. vesiculosus varied during the season with the highest value achieved in early autumn (September) (Connan et al. 2004).

470 On the other hand, SE using the same solvent as PLE gave nearly the same TPC value ( $p>$ 471 0.05), again confirming the advantages of PLE.

473 Radical scavenging ability of the phenolic PLE extracts in this study were lower than some 474 literatures as shown with DPPH and ABTS EC50 comparison (Sabeena Farvin and Jacobsen 475 2013; Hermund et al. 2018; Ferreira et al. 2019). This study reported higher EC50 value for 476 both stable radicals which mean more antioxidant was needed to achieve the same inhibition 
477 level. The variation might be resulted from the lower selectivity of PLE compared to SE which 478 was already shown by low DPPH inhibition activity for sample with high yield and TPC value. 479 In comparison, DPPH and ABTS EC50 values for PLE were higher than SE with the same 480 ethanol concentration as also observed on another study (Tierney et al. 2013).

481

482 The metal chelating EC50 value of extract from SE on another study was reported to be 87.7 $483 \mu \mathrm{g} \mathrm{mL}^{-1}$ for $80 \%$ ethanolic extract which was quite similar to the result of the same experiment 484 in this study (Hermund et al. 2018). Some example of good natural chelators are citric acid, 485 phospholipids and amino acid/peptides/proteins (Berdahl et al. 2010). Aqueous extract of $F$. 486 vesiculosus has been proven to contain small peptides, with molecular weight between 204 and $487740 \mathrm{Da}$ (André et al. 2020). Phospholipids are best extracted using organic solvent with high 488 polarity such as ethanol, acetone and ethyl acetate (Zhou and Rakariyatham 2018). Therefore, 489 SE extract using $80 \%$ ethanol had highest metal chelation ability because more phospholipids extracted. decreases monotonically with increasing concentration of ethanol in water-ethanol mixture (Zuorro et al. 2019) which explains absence of caffeic acid in all extracts which were extracted with ethanolic solvents. It was also reported in previous study that ethanolic extracts generally contained higher concentration of phenolic acids but lower number of different phenolic acids 
503

504

505

\section{Conclusions}

515

516

517

518

when compared to water extracts (Sabeena Farvin and Jacobsen 2013). This phenomenon was not found in this study due to smaller range of polarity difference between the solvent used.

The discovery that SE with $58.65 \%$ ethanol extracted more gallic acid than PLE with the same ethanol concentration and SE with $80 \%$ ethanol showed that gallic acid polarity is closer to the polarity of $58.65 \%$ ethanol solution rather than other solutions studied. Gallic acid is classified as a polar phenolic compound; thus it is more soluble in solvent of higher polarity (Yeop et al. 2017). Polarity of solvent in PLE decrease because of diminishing hydrogen bond strength in subcritical area (Marcus 2018), which explained lower concentration of gallic acid in PLE for the same solvent. The polarity of $58.65 \%$ ethanol in PLE condition of this study might be similar to $80 \%$ ethanol in unpressurized condition, which was shown by similar amount of gallic acid extracted for these two conditions.

In this study, phenolic compounds with high antioxidant activity have been successfully extracted from Fucus vesiculosus with PLE method. Effect of temperature, ethanol concentration and extraction time on extraction yield, TPC, DPPH and ABTS radicals scavenging activity and metal chelating activity have been modelled using Box Behnken experimental design and proved to be statistically significant with ANOVA analysis. These models can act as a cornerstone for different aims, either for maximizing TPC or maximizing antioxidant properties, with a little error. However, this study focused on maximizing the extraction of phenolics with average antioxidant activities. The models could predict phenolic compounds yield and antioxidant activities values with little error, which showed the robustness and accuracy of the mathematical models. This study also observed that PLE could extract phenolic compounds with higher yield and TPC compared to SE although SE required 
526 longer extraction time and higher solvent requirement. The extract obtained from PLE had the 527 same radical scavenging ability and lower metal chelating ability in comparison with SE extract.

528 Moreover, when the PLE extract was analysed with HPLC, gallic, protocatechuic and gentisic 529 acids were detected.

530 This study was one of the first to apply PLE for extracting phenolic compounds from $F$.

531 vesiculosus. Therefore, many further studies are still needed to give better understanding 532 especially to justify the low selectivity of PLE with analysis of polysaccharides and proteins in 533 the samples. For implementation of PLE in a larger scale, a study is needed to avoid filter 534 blockage observed in this study due to water presence in solvent. It is interesting to study PLE 535 as one stage of biorefinery to extract more than one product together with other extraction 536 method, e.g. enzymatic assisted extraction, and observe the effect of this combination on the 537 antioxidant properties. Finally, application of antioxidant extract from PLE in food or 538 pharmaceutical products are needed to study the effecacy of this extract to inhibit lipid 539 oxidation.

540 Compliance with ethical standards

541 Conflict of interest The authors declare that there is no conflict of interest regarding the 542 publication of this article.

\section{$543 \quad$ Funding}

544 This work has received funding from the European Union's Horizon 2020 research and 545 innovation program under the Marie Sklodowska-Curie grant agreement no. 713683 546 (COFUNDfellowsDTU)

547 Acknowledgements

548 The authors thank Susan Løvstad Holdt for providing seaweed used in this study. All authors 549 would also thank Inge Holmberg and Thi Thu Trang Vu for their support and training on all 550 antioxidant properties. 


\section{References}

Alvarez-Rivera G, Bueno M, Ballesteros-Vivas D, Mendiola JA, Ibañez E (2020) Pressurized liquid extraction. Liq Extr 375-398

Amarante SJ, Catarino MD, Marçal C, Silva AMS, Ferreira R, Cardoso SM (2020) Microwaveassisted extraction of phlorotannins from Fucus vesiculosus. Mar Drugs 18:559

André R, Guedes L, Melo R, Ascensão L, Pacheco R, Vaz PD, Serralheiro ML (2020) Effect of food preparations on in vitro bioactivities and chemical components of Fucus vesiculosus. Foods 9:1-20

Battistella Lasta HF, Lentz L, Gonçalves Rodrigues LG, Mezzomo N, Vitali L, Salvador Ferreira SR (2019) Pressurized liquid extraction applied for the recovery of phenolic compounds from beetroot waste. Biocatal Agric Biotechnol 21:1-9

Berdahl DR, Nahas RI, Barren JP (2010) Synthetic and natural antioxidant additives in food stabilization: Current applications and future research. In: Decker EA (ed) Oxidation in foods and beverages and antioxidant applications: understanding mechanisms of oxidation and antioxidant activity. Woodhead Publishing Limited, Cambridge, pp 272320

Castro-Alves VC, Cordenunsi BR (2015) Total soluble phenolic compounds quantification is not as simple as it seems. Food Anal Methods 8:873-884

Catarino MD, Silva AMS, Mateus N, Cardoso SM (2019) Optimization of phlorotannins extraction from Fucus vesiculosus and evaluation of their potential to prevent metabolic disorders. Mar Drugs 17:1-23

Connan S, Goulard F, Stiger V, Deslandes E, Gall EA (2004) Interspecific and temporal variation in phlorotannin levels in an assemblage of brown algae. Bot Mar 47:410-416

De Paepe D, Valkenborg D, Coudijzer K, Noten B, Servaes K, De Loose M, Voorspoels S, Diels L, Van Droogenbroeck B (2014) Thermal degradation of cloudy apple juice 

phenolic constituents. Food Chem 162:176-185

577 Ferreira RM, Ribeiro AR, Patinha C, Silva AMS, Cardoso SM, Costa R (2019) Water 578 extraction kinetics of bioactive compounds of Fucus vesiculosus. Molecules 24:1-15

579 Hermund DB, Heung SY, Thomsen BR, Akoh CC, Jacobsen C (2018) Improving oxidative 580 stability of skin-care emulsions with antioxidant extracts from brown alga Fucus 581 vesiculosus. JAOCS, J Am Oil Chem Soc 95:1509-1520

582 Holdt SL, Kraan S (2011) Bioactive compounds in seaweed : functional food applications and $583 \quad$ legislation. J Appl Phycol 23:543-597

584 Howard L, Pandjaitan N (2008) Pressurized liquid extraction of flavonoids from spinach. J $585 \quad$ Food Sci 73:151-157

586 Ilyasov IR, Beloborodov VL, Selivanova IA, Terekhov RP (2020) ABTS/PP decolorization 587 assay of antioxidant capacity reaction pathways. Int J Mol Sci 21:1-27

588 Imbs TI, Skriptsova A V., Zvyagintseva TN (2014) Antioxidant activity of fucose-containing 589 sulfated polysaccharides obtained from Fucus evanescens by different extraction methods. ability of in vitro antioxidant assays to predict the efficiency of a cod protein hydrolysate and brown seaweed extract to prevent oxidation in marine food model systems. J Sci Food 
Agric 96:2125-2135

602 Kamali H, Ahmadzadeh Sani T, Mohammadi A, Alesheikh P, Khodaverdi E, Hadizadeh F 603 (2018) A comparison between pressurized hot water and pressurized liquid extraction for 604 optimizing phenolic and antioxidants capacity of the wooden layer between of walnut

605 seed. J Supercrit Fluids 133:535-541

Karadağ A, Hermund DB, Jensen LHS, Andersen U, Jónsdóttir R, Kristinsson HG, Alasalvar C, Jacobsen C (2017) Oxidative stability and microstructure of 5\% fish-oil-enriched granola bars added natural antioxidants derived from brown alga Fucus vesiculosus. Eur J Lipid Sci Technol 119:1-12

Koivikko R, Loponen J, Honkanen T, Jormalainen V (2005) Contents of soluble, cell-wallbound and exuded phlorotannins in the brown alga Fucus vesiculosus, with implications on their ecological functions. J Chem Ecol 31:195-212

Luthria DL (2012) Optimization of extraction of phenolic acids from a vegetable waste product using a pressurized liquid extractor. J Funct Foods 4:842-850

Marcus Y (2018) Extraction by subcritical and supercriticalwater, methanol, ethanol and their mixtures. Separations 5:1-18

Meichssner R, Stegmann N, Cosin AS, Sachs D, Bressan M, Marx H, Krost P, Schulz R (2020) Control of fouling in the aquaculture of Fucus vesiculosus and Fucus serratus by regular desiccation. J Appl Phycol 32:4145-4158

Monteiro M, Santos RA, Iglesias P, Couto A, Serra CR, Gouvinhas I, Barros A, Oliva-Teles A, Enes P, Díaz-Rosales P (2020) Effect of extraction method and solvent system on the phenolic content and antioxidant activity of selected macro- and microalgae extracts. $\mathbf{J}$ Appl Phycol 32:349-362

Moroney NC, O’Grady MN, Lordan S, Stanton C, Kerry JP (2015) Seaweed polysaccharides (laminarin and fucoidan) as functional ingredients in pork meat: an evaluation of anti- 
oxidative potential, thermal stability and bioaccessibility. Mar Drugs 13:2447-2464

627

628

629

630

631

632

633

634

635

636

637

638

639

640

641

642

643

644

645

646

647

648

649

650

Mustafa A, Turner C (2011) Pressurized liquid extraction as a green approach in food and herbal plants extraction: a review. Anal Chim Acta 703:8-18

Olatunji O (2020) Laminarins. In: Olatunji O (ed) Aquatic Biopolymers. Springer International Publishing, Cham, pp 189-210

Pangestuti R, Getachew AT, Siahaan EA, Chun BS (2019) Characterization of functional materials derived from tropical red seaweed Hypnea musciformis produced by subcritical water extraction systems. J Appl Phycol 31:2517-2528

Pavez IC, Lozano-Sánchez J, Borrás-Linares I, Nuñez H, Robert P, Segura-Carretero A (2019) Obtaining an extract rich in phenolic compounds from olive pomace by pressurized liquid extraction. Molecules 24:1-17

Plaza M, Marina ML (2019) Pressurized hot water extraction of bioactives. TrAC - Trends Anal Chem 116:236-247

Plaza M, Turner C (2017) Pressurized hot water extraction of bioactives. Compr Anal Chem $76: 53-82$

Sabeena Farvin KH, Jacobsen C (2013) Phenolic compounds and antioxidant activities of selected species of seaweeds from Danish coast. Food Chem 138:1670-1681

Saha S, Singh AK, Keshari AK, Raj V, Rai A, Maity S (2017) Modern extraction techniques for drugs and medicinal agents. In: Grumezescu AM, Holban AM (eds) Ingredients extraction by physico-chemical methods in food. Elsevier Inc., London, pp 65-106

Sánchez-Camargo ADP, Montero L, Stiger-Pouvreau V, Tanniou A, Cifuentes A, Herrero M, Ibáñez E (2016) Considerations on the use of enzyme-assisted extraction in combination with pressurized liquids to recover bioactive compounds from algae. Food Chem 192:6774

Santos DT, Veggi PC, Meireles MAA (2012) Optimization and economic evaluation of 
pressurized liquid extraction of phenolic compounds from jabuticaba skins. J Food Eng $108: 444-452$

Stengel DB, Connan S (2015) Natural products from marine algae: methods and protocols. Nat Prod From Mar Algae Methods Protoc 1308:1-439

Teo CC, Tan SN, Yong JWH, Hew CS, Ong ES (2010) Pressurized hot water extraction (PHWE). J Chromatogr A 1217:2484-2494

Terpinc P, Čeh B, Ulrih NP, Abramovič H (2012) Studies of the correlation between antioxidant properties and the total phenolic content of different oil cake extracts. Ind Crops Prod 39:210-217

Tierney MS, Smyth TJ, Hayes M, Soler-Vila A, Croft AK, Brunton N (2013) Influence of pressurised liquid extraction and solid-liquid extraction methods on the phenolic content and antioxidant activities of Irish macroalgae. Int J Food Sci Technol 48:860-869

Tripodo G, Ibáñez E, Cifuentes A, Gilbert-López B, Fanali C (2018) Optimization of pressurized liquid extraction by response surface methodology of goji berry (Lycium barbarum L.) phenolic bioactive compounds. Electrophoresis 39:1673-1682

Ummat V, Tiwari BK, Jaiswal AK, Condon K, Garcia-Vaquero M, O’Doherty J, O’Donnell C, Rajauria G (2020) Optimisation of ultrasound frequency, extraction time and solvent for the recovery of polyphenols, phlorotannins and associated antioxidant activity from brown seaweeds. Mar Drugs 18:1-15

Vo Dinh T, Saravana PS, Woo HC, Chun BS (2018) Ionic liquid-assisted subcritical water enhances the extraction of phenolics from brown seaweed and its antioxidant activity. Sep Purif Technol 196:287-299

Wang T, Jónsdóttir R, Liu H, Gu L, Kristinsson HG, Raghavan S, Ólafsdóttir G (2012) Antioxidant capacities of phlorotannins extracted from the brown algae Fucus vesiculosus. J Agric Food Chem 60:5874-5883 
676 Wikström SA, Kautsky L (2007) Structure and diversity of invertebrate communities in the 677 presence and absence of canopy-forming Fucus vesiculosus in the Baltic Sea. Estuar Coast $678 \quad$ Shelf Sci 72:168-176

679 Yeop A, Sandanasam J, Pan SF, Abdulla S, Yusoff MM, Gimbun J (2017) The effect of particle 680 size and solvent type on the gallic acid yield obtained from Labisia pumila by ultrasonic 681 extraction. MATEC Web Conf 111:1-5

682 Yuan Y V., Bone DE, Carrington MF (2005) Antioxidant activity of dulse (Palmaria palmata) 683 extract evaluated in vitro. Food Chem 91:485-494

684 Yugay YA, Usoltseva R V., Silant'ev VE, Egorova AE, Karabtsov AA, Kumeiko V V., 685 Ermakova SP, Bulgakov VP, Shkryl YN (2020) Synthesis of bioactive silver 686 nanoparticles using alginate, fucoidan and laminaran from brown algae as a reducing and 687 stabilizing agent. Carbohydr Polym 245:116547

688 Zhou DY, Rakariyatham K (2018) Phospholipids. Encycl Food Chem 3:546-549

689 Zuorro A, Iannone A, Lavecchia R (2019) Water-organic solvent extraction of phenolic $690 \quad$ antioxidants from brewers'spent grain. Processes 7:126

691

692

693

694

695

696

697

698

699

700

701 


\section{Figure Captions}

703 Fig. 1 Effect of extraction time, temperature and ethanol concentration in solvent on TPC value

704 of extracts (mean $\pm \mathrm{SD} ; \mathrm{n}=6)$

705 Fig. 2 Effect of extraction temperature, time and ethanol concentration in solvent on (a) and 706 (b) extraction yield; (c) and (d) TPC value; (e) and (f) DPPH inhibition activity at $0.5 \mathrm{mg} \mathrm{mL}^{-}$

$707 \stackrel{1}{1}$ (g) and (h) ABTS inhibition activity at $0.5 \mathrm{mg} \mathrm{mL}^{-1}$; (i) and (j) metal chelating activity at 1.5 $708 \mathrm{mg} \mathrm{mL}-1$

709 Fig. 3 Scatter plot for all 51 randomized set of solutions, pink color: first potential solution, 710 blue color: second potential solution, green color: third potential solution, orange color: fourth 711 potential solution.

712 Fig. 4. Amount of six phenolic acids in extracts (mean \pm SD; $n=3$ ) obtained from PLE and SE 


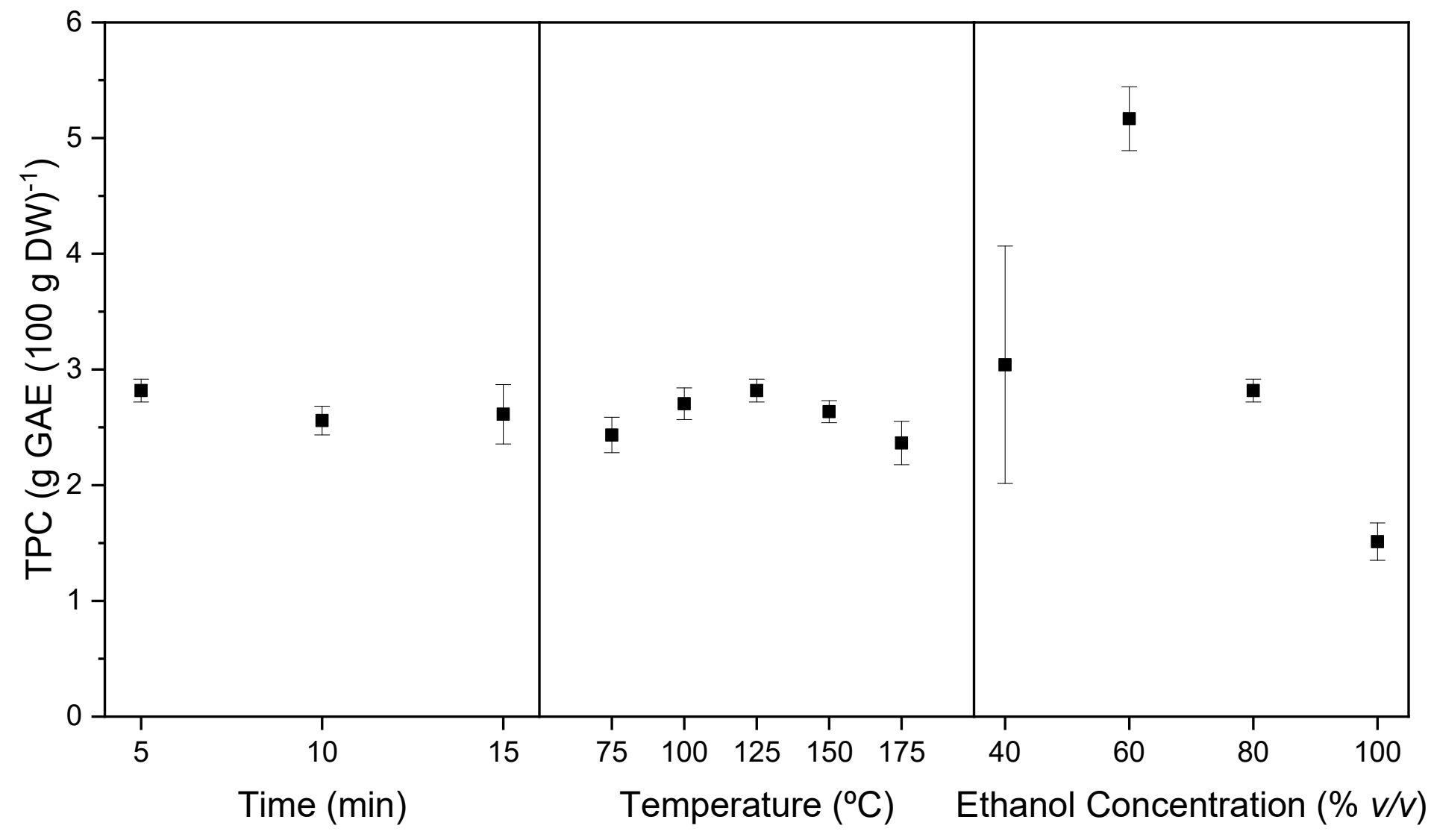

Fig. 1 


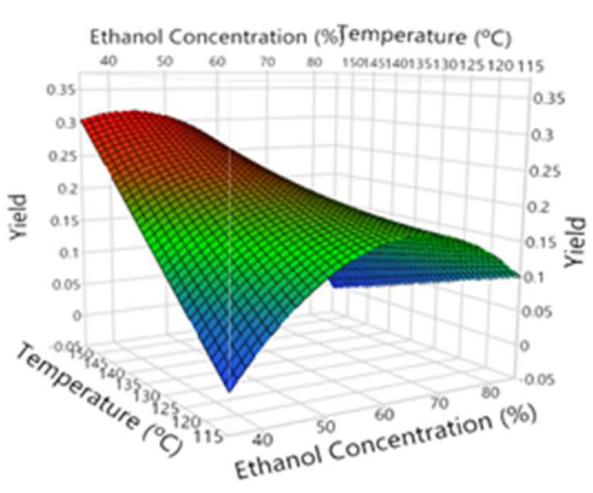

(a)

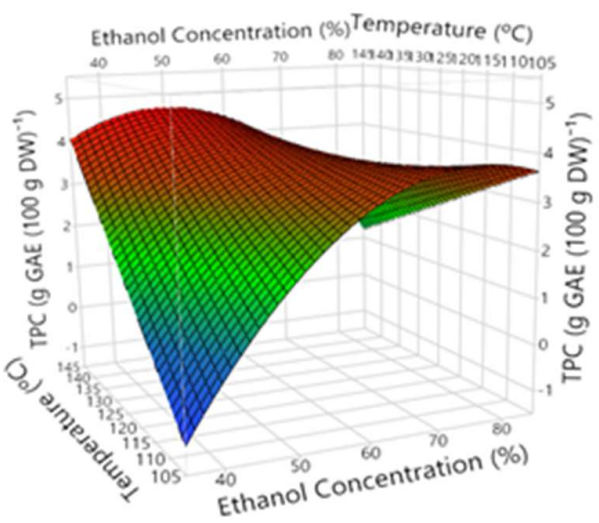

(c)

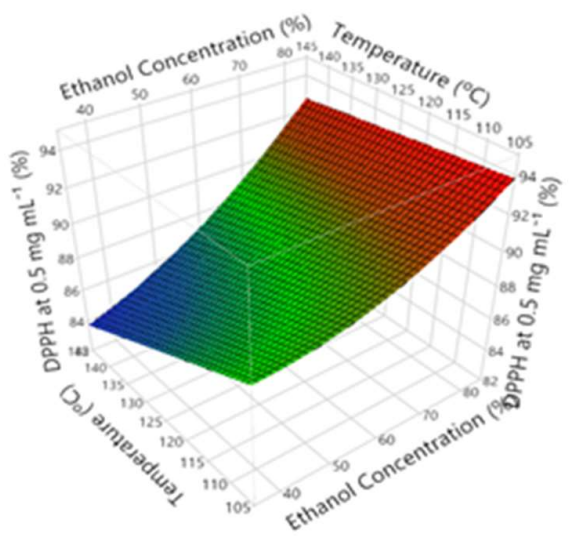

(e)

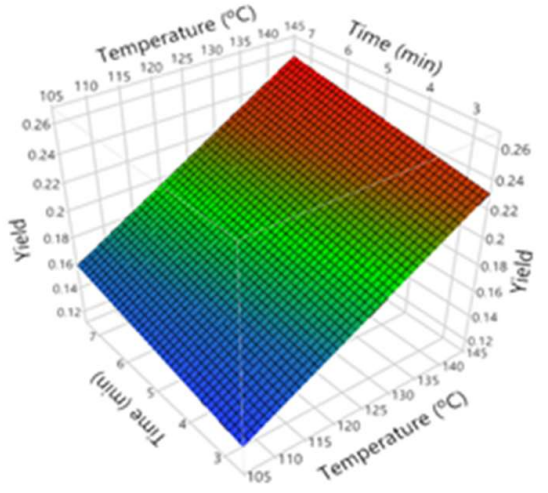

(b)

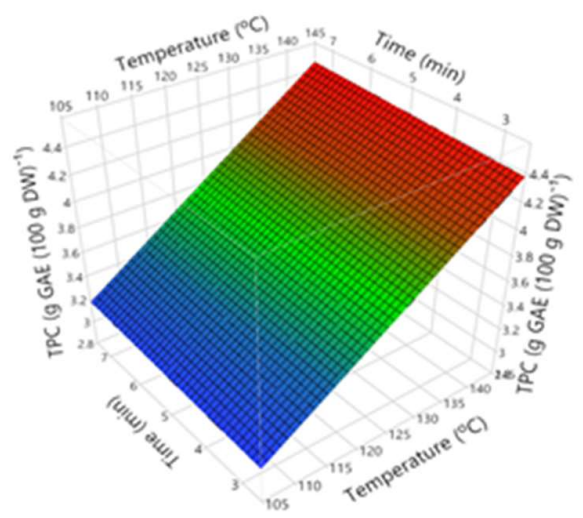

(d)

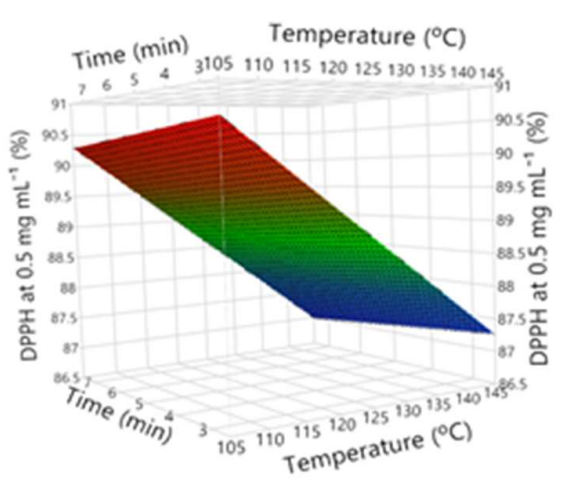

(f) 


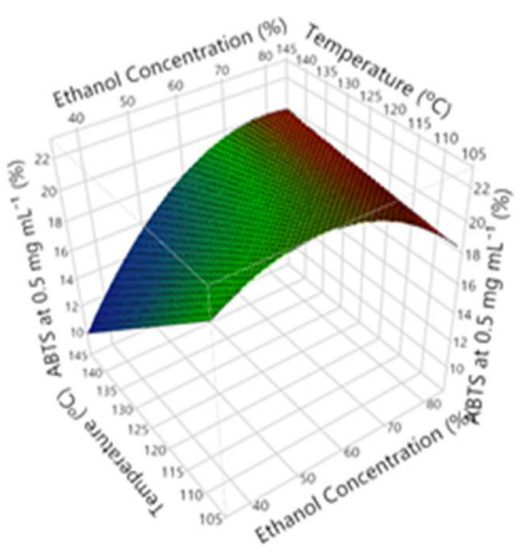

(g)

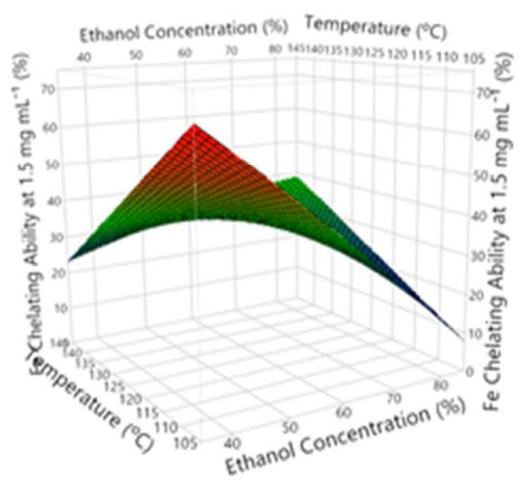

(i)

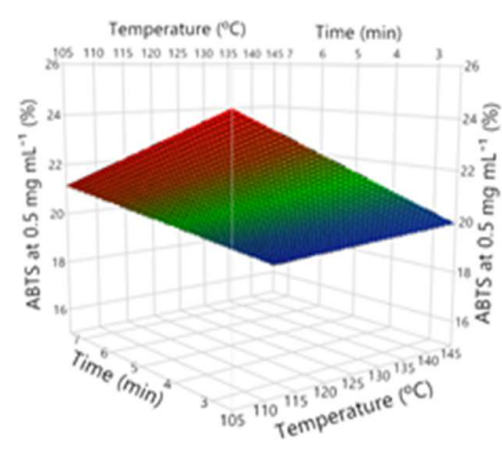

(h)

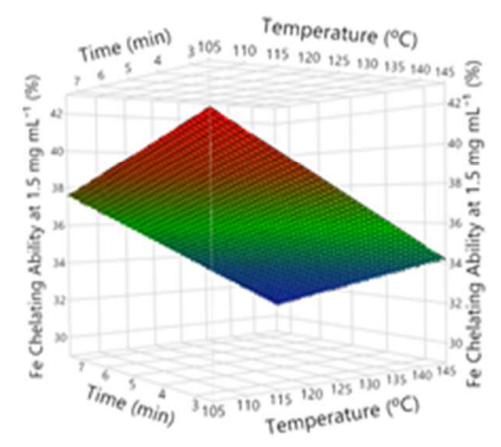

(j)

Fig. 2 


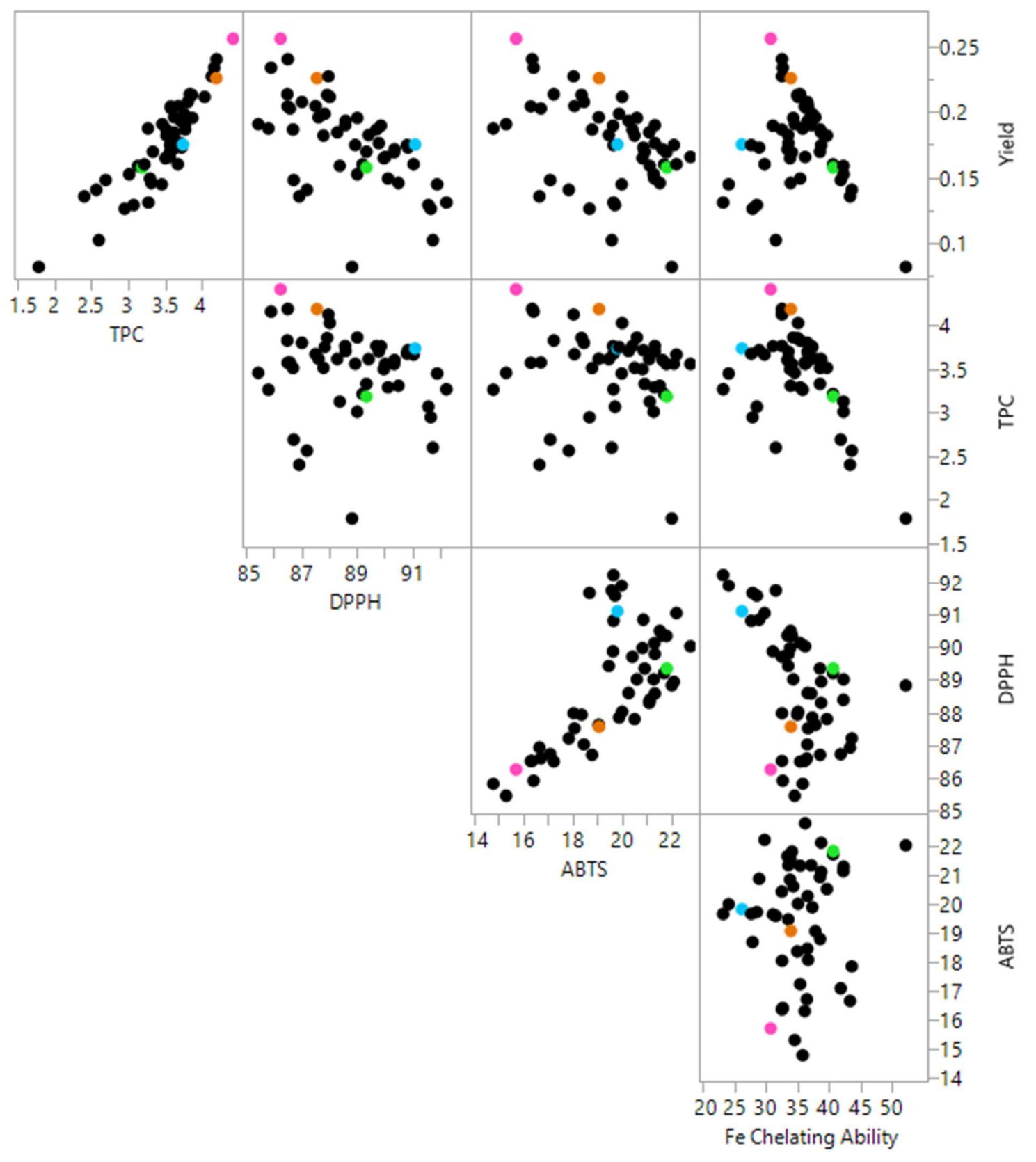

Fig. 3 


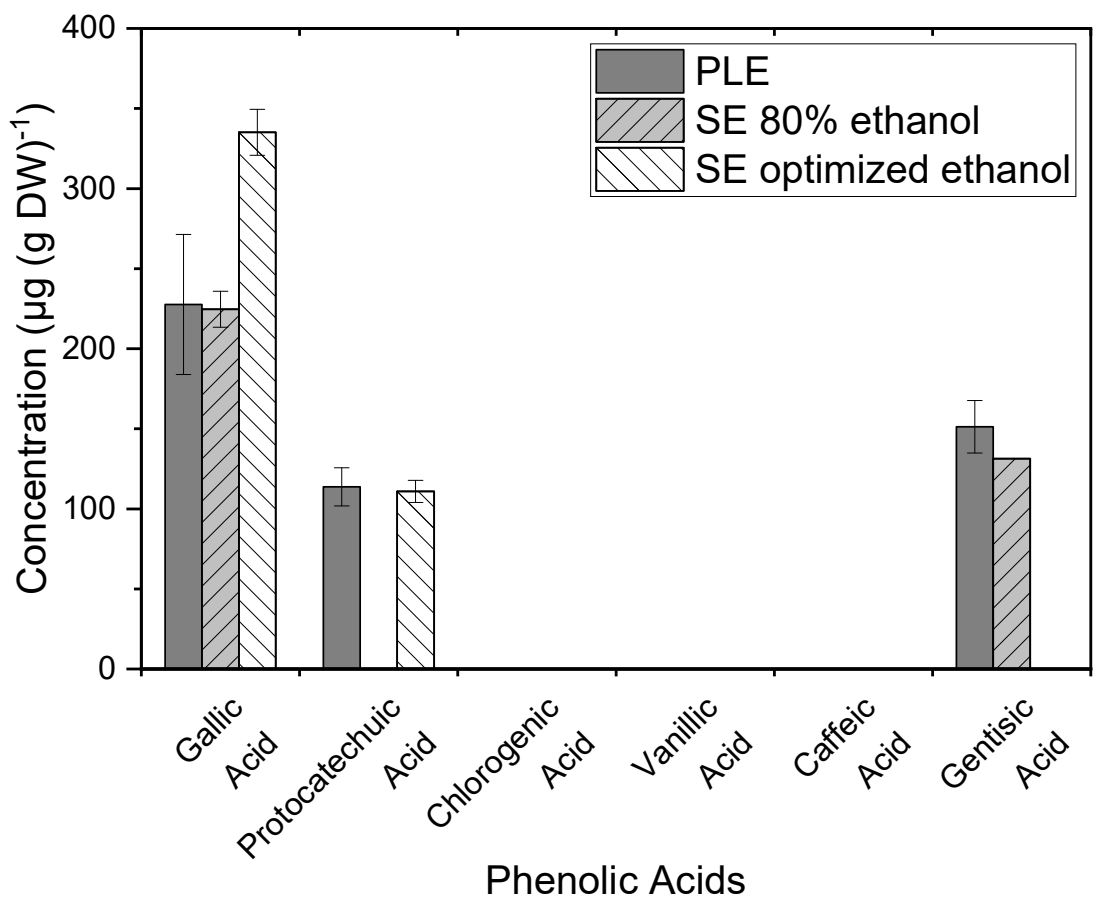

724

725

Fig. 4 
Table 1. Box-Behnken experimental design and experiment results (mean $\pm \mathrm{SD} ; \mathrm{n}=3$ ) of extract antioxidant properties with variations of ethanol concentration, temperature and extraction time

\begin{tabular}{|c|c|c|c|c|c|c|c|c|}
\hline \multirow[b]{2}{*}{$\begin{array}{c}\text { Extract } \\
\text { No. }\end{array}$} & \multicolumn{3}{|c|}{ Independent Variables } & \multirow[b]{2}{*}{$\begin{array}{l}\text { Dry Basis } \\
\text { Yield (\%) }\end{array}$} & \multirow[b]{2}{*}{$\begin{array}{c}\text { TPC (g GAE } \\
\left(100 \mathrm{~g} \mathrm{DW}^{-1}\right)\end{array}$} & \multirow[b]{2}{*}{$\begin{array}{c}\text { DPPH at } 0.5 \\
\mathrm{mg} \mathrm{mL}^{-1}(\% \\
\text { inhibition) }\end{array}$} & \multirow[b]{2}{*}{$\begin{array}{c}\text { ABTS at } 0.5 \\
\mathrm{mg} \mathrm{mL}^{-1}(\% \\
\text { inhibition })\end{array}$} & \multirow[b]{2}{*}{$\begin{array}{c}\mathrm{Fe}^{2+} \text { Chelating } \\
\text { Ability at } 1.5 \mathrm{mg} \\
\mathrm{mL}^{-1}(\%)\end{array}$} \\
\hline & $\begin{array}{c}\text { Ethanol } \\
\text { concentration } \\
(\% v / v)-\mathbf{E} \\
\end{array}$ & $\begin{array}{l}\text { Tempe- } \\
\text { rature } \\
\left({ }^{\circ} \mathrm{C}\right)-\mathrm{T}\end{array}$ & $\begin{array}{c}\text { Time } \\
(\min ) \\
-t \\
\end{array}$ & & & & & \\
\hline 1 & $40(-1)$ & $110(-1)$ & $5(0)$ & 4.49 & $0.74 \pm 0.02$ & $87.5 \pm 1.0$ & $21.2 \pm 5.3$ & $56.8 \pm 7.3$ \\
\hline 2 & $40(-1)$ & $140(1)$ & $5(0)$ & 22.32 & $4.52 \pm 0.06$ & $86.0 \pm 0.3$ & $12.4 \pm 0.8$ & $21.9 \pm 3.4$ \\
\hline 3 & $80(1)$ & $110(-1)$ & $5(0)$ & 13.78 & $3.17 \pm 0.06$ & $92.0 \pm 0.6$ & $19.6 \pm 1.7$ & $35.0 \pm 12.0$ \\
\hline 4 & $80(1)$ & $140(1)$ & $5(0)$ & 6.56 & $2.51 \pm 0.06$ & $93.1 \pm 0.8$ & $18.7 \pm 1.7$ & $32.6 \pm 15.8$ \\
\hline 5 & $60(0)$ & $110(-1)$ & $3(-1)$ & 11.63 & $3.43 \pm 0.11$ & $90.7 \pm 0.8$ & $24.1 \pm 2.1$ & $31.8 \pm 1.5$ \\
\hline 6 & $60(0)$ & $110(-1)$ & $7(1)$ & 14.06 & $4.06 \pm 0.19$ & $90.9 \pm 0.5$ & $19.6 \pm 4.2$ & $34.7 \pm 5.5$ \\
\hline 7 & $60(0)$ & $140(1)$ & $3(-1)$ & 18.55 & $3.99 \pm 0.10$ & $86.6 \pm 4.1$ & $20.2 \pm 1.4$ & $46.9 \pm 3.9$ \\
\hline 8 & $60(0)$ & $140(1)$ & $7(1)$ & 26.09 & $4.24 \pm 0.04$ & $85.5 \pm 2.8$ & $18.7 \pm 0.7$ & $32.8 \pm 0.4$ \\
\hline 9 & $40(-1)$ & $125(0)$ & $3(-1)$ & 12.38 & $2.30 \pm 0.06$ & $86.8 \pm 1.9$ & $18.3 \pm 0.6$ & $52.5 \pm 5.3$ \\
\hline 10 & $80(1)$ & $125(0)$ & $3(-1)$ & 12.52 & $3.08 \pm 0.11$ & $91.8 \pm 1.0$ & $22.4 \pm 1.2$ & $28.3 \pm 2.0$ \\
\hline 11 & $40(-1)$ & $125(0)$ & $7(1)$ & 10.30 & $1.62 \pm 0.09$ & $86.7 \pm 1.3$ & $16.3 \pm 0.8$ & $49.0 \pm 1.7$ \\
\hline 12 & $80(1)$ & $125(0)$ & $7(1)$ & 12.93 & $3.16 \pm 0.10$ & $91.9 \pm 0.6$ & $18.8 \pm 2.8$ & $24.1 \pm 7.1$ \\
\hline 13 & $60(0)$ & $125(0)$ & $5(0)$ & 18.76 & $3.12 \pm 0.17$ & $89.5 \pm 1.4$ & $21.7 \pm 0.7$ & $43.4 \pm 2.4$ \\
\hline 14 & $60(0)$ & $125(0)$ & $5(0)$ & 20.50 & $3.91 \pm 0.14$ & $89.7 \pm 1.6$ & $19.4 \pm 0.1$ & $36.7 \pm 2.9$ \\
\hline 15 & $60(0)$ & $125(0)$ & $5(0)$ & 26.42 & $3.67 \pm 0.07$ & $88.5 \pm 1.6$ & $20.0 \pm 0.5$ & $38.7 \pm 5.7$ \\
\hline
\end{tabular}


Table 2. Independent variables with predicted values and desirability of each antioxidant property for four selected potential solutions

\begin{tabular}{|c|c|c|c|c|c|c|c|c|c|c|}
\hline $\begin{array}{c}\text { Color } \\
\text { in Fig. } \\
\quad 3\end{array}$ & $\begin{array}{c}\text { Ethanol } \\
\text { Conc. } \\
(\% \text { v } / v)\end{array}$ & $\mathrm{T}\left({ }^{\circ} \mathrm{C}\right)$ & $\begin{array}{l}\text { Time } \\
\text { (min) }\end{array}$ & $\begin{array}{c}\text { TPC } \\
(\mathrm{g} \\
\text { GAE } \\
(100 \mathrm{~g} \\
\left.\text { DW })^{-1}\right)\end{array}$ & $\begin{array}{c}\text { DPPH at } \\
0.5 \mathrm{mg}^{-1} \\
\mathrm{~mL}^{-1} \\
(\%)\end{array}$ & $\begin{array}{c}\mathrm{Fe}^{2+} \\
\text { Chelating } \\
\text { Ability at } \\
1.5 \mathrm{mg} \\
\mathrm{mL}^{-1}(\%)\end{array}$ & $\begin{array}{c}\text { Desira } \\
\text { bility }\end{array}$ & $\begin{array}{c}\text { TPC } \\
\text { Desira } \\
\text { bility }\end{array}$ & $\begin{array}{c}\text { DPPH } \\
\text { Desira } \\
\text { bility }\end{array}$ & $\begin{array}{c}\mathrm{Fe}^{2+} \\
\text { Chela- } \\
\text { ting } \\
\text { Ability } \\
\text { Desira } \\
\text { bility }\end{array}$ \\
\hline Pink & & 140.00 & 7.00 & 4.420 & & 30 & 0.5007 & 0.8564 & 0.1857 & 0.5179 \\
\hline Blue & 71.59 & 114.02 & 6.82 & 3.741 & 91.11 & 26.22 & 0.6035 & 0.7087 & 0.6691 & 0.4029 \\
\hline Green & 56.74 & 113.69 & 5.03 & 3.188 & 89.36 & 40.66 & 0.6154 & 0.5907 & 0.4855 & 0.7190 \\
\hline Orange & 58.65 & 137.18 & 4.68 & 4.193 & 87.57 & 33.97 & 0.5991 & 0.8070 & 0.3106 & 0.5873 \\
\hline
\end{tabular}

731

732 
Table 3. Actual experiment results of optimized PLE (mean $\pm S D ; n=3$, except $n=9$ for TPC) and the predicted value from mathematical models

\begin{tabular}{|l|c|c|}
\hline \multicolumn{1}{|c|}{ Parameter } & Actual & Predicted \\
\hline Dry Basis Yield $(\%)$ & $31.16 \pm 3.20$ & 22.6 \\
\hline TPC $\left(\mathrm{g}\right.$ GAE $\left.(100 \mathrm{~g} \mathrm{DW})^{-1}\right)$ & $3.69 \pm 0.30$ & 4.19 \\
\hline DPPH at $0.5 \mathrm{mg} \mathrm{mL}^{-1}(\%$ inhibition$)$ & $86.7 \pm 1.9$ & 87.6 \\
\hline ABTS at $0.5 \mathrm{mg} \mathrm{mL}^{-1}(\%$ inhibition) & $16.2 \pm 1.3$ & 19.1 \\
\hline $\mathrm{Fe}^{2+}$ Chelating Ability at $1.5 \mathrm{mg} \mathrm{mL}^{-1}(\%)$ & $46.3 \pm 6.8$ & 33.4 \\
\hline
\end{tabular}


Table 4. Comparison of extraction yield and each antioxidant properties between PLE and SE (mean \pm SD; $n=3$, except $n=9$ for TPC)

\begin{tabular}{|c|c|c|c|c|c|}
\hline Extract & $\begin{array}{c}\text { Dry Basis Yield } \\
(\%)\end{array}$ & $\begin{array}{c}\text { TPC (g GAE } \\
\left(100 \mathrm{~g} \mathrm{DW}^{-1}\right)\end{array}$ & $\begin{array}{c}\text { DPPH EC50 } \\
\left(\mu \mathrm{g} \mathrm{mL} \mathbf{~}^{-1}\right)\end{array}$ & $\begin{array}{c}\text { ABTS EC50 } \\
\left(\mathrm{mg} \mathrm{mL}^{-1}\right)\end{array}$ & $\begin{array}{c}\mathrm{Fe}^{2+} \text { Chelating EC50 } \\
\left(\mu \mathrm{g} \mathrm{mL} \mathrm{L}^{-1}\right)\end{array}$ \\
\hline Optimized PLE & $31.16 \pm 3.20$ & $3.69 \pm 0.30$ & $92.6 \pm 11.5$ & $2.35 \pm 0.15$ & $1100.2 \pm 103.5$ \\
\hline SE with optimized ethanol concentration & $30.75 \pm 2.36$ & $3.41 \pm 0.24$ & $86.6 \pm 5.6$ & $2.11 \pm 0.23$ & $334.1 \pm 152.5$ \\
\hline SE with $80 \% v / v$ ethanol & $20.35 \pm 1.15$ & $2.53 \pm 0.18$ & $97.2 \pm 47.0$ & $2.74 \pm 0.74$ & $96.6 \pm 24.0$ \\
\hline
\end{tabular}

737 
Table S.1. Analysis of variance (ANOVA) of each independent variable and their derivations for overall models built

\begin{tabular}{|c|c|c|}
\hline Parameter & $\begin{array}{c}\boldsymbol{p} \text { value before insignificance } \\
\text { removal }\end{array}$ & $\begin{array}{c}\boldsymbol{p} \text { value after } \\
\text { insignificance removal }\end{array}$ \\
\hline $\mathrm{E}$ & 0.00384 & 0.00014 \\
\hline $\mathrm{E}^{*} \mathrm{E}$ & 0.00971 & 0.00161 \\
\hline $\mathrm{E}^{*} \mathrm{~T}$ & 0.01342 & 0.00172 \\
\hline $\mathrm{T}$ & 0.03700 & 0.01475 \\
\hline $\mathrm{E}^{*} \mathrm{t}$ & 0.18040 & 0.18807 \\
\hline $\mathrm{t}$ & 0.21223 & \\
\hline $\mathrm{T}^{*} \mathrm{~T}$ & 0.29031 & \\
\hline $\mathrm{t}^{*} \mathrm{t}$ & 0.33431 & \\
\hline $\mathrm{T}^{*} \mathrm{t}$ & 0.52089 & \\
\hline
\end{tabular}

751

752 Using $p$ value of 0.05 as limit of statistically significance, terms of $\left(\mathrm{E}^{*} \mathrm{t}\right),\left(\mathrm{T}^{*} \mathrm{~T}\right),\left(\mathrm{t}^{*} \mathrm{t}\right)$ and $\left(\mathrm{T}^{*} \mathrm{t}\right)$

753 were not statistically significant to the models produced. They were excluded from the 754 mathematical models, while time was still included although it was not significant because it 755 needed to be optimized. 
Table S.2. Comparison between actual experimental and predicted results from mathematical models

\begin{tabular}{|c|c|c|c|c|c|c|c|c|c|c|c|c|c|}
\hline \multirow{2}{*}{$\begin{array}{l}\text { Extract } \\
\text { No. }\end{array}$} & \multicolumn{3}{|c|}{ Independent Variables } & \multicolumn{2}{|c|}{ Dry Basis Yield (\%) } & \multicolumn{2}{|c|}{$\begin{array}{c}\text { TPC (g GAE (100 g } \\
\text { DW)-1) }\end{array}$} & \multicolumn{2}{|c|}{$\begin{array}{c}\text { DPPH at } 0.5 \mathrm{mg} \mathrm{mL}^{-1} \\
(\% \text { inhibition })\end{array}$} & \multicolumn{2}{|c|}{$\begin{array}{c}\text { ABTS at } 0.5 \mathrm{mg} \mathrm{mL}^{-1} \\
(\% \text { inhibition })\end{array}$} & \multicolumn{2}{|c|}{$\begin{array}{l}\mathrm{Fe}^{2+} \text { Chelating Ability } \\
\text { at } 1.5 \mathrm{mg} \mathrm{mL}^{-1}(\%)\end{array}$} \\
\hline & $\begin{array}{c}E \\
(\% v / v)\end{array}$ & $\begin{array}{c}\mathrm{T} \\
\left({ }^{\circ} \mathrm{C}\right)\end{array}$ & $\begin{array}{c}t \\
(\min )\end{array}$ & Actual & Predicted & Actual & Predicted & Actual & Predicted & Actual & Predicted & Actual & Predicted \\
\hline 1 & 40 & 110 & 5 & 4.49 & 2.42 & $0.74 \pm 0.02$ & 0.70 & $87.5 \pm 1.0$ & 88.6 & $21.2 \pm 5.3$ & 20.8 & $56.8 \pm 7.3$ & 58.0 \\
\hline 2 & 40 & 140 & 5 & 22.32 & 22.33 & $4.52 \pm 0.06$ & 3.89 & $86.0 \pm 0.3$ & 84.9 & $12.4 \pm 0.8$ & 13.3 & $21.9 \pm 3.4$ & 29.9 \\
\hline 3 & 80 & 110 & 5 & 13.78 & 14.02 & $3.17 \pm 0.06$ & 3.61 & $92.0 \pm 0.6$ & 92.8 & $19.6 \pm 1.7$ & 19.7 & $35.0 \pm 12.0$ & 17.3 \\
\hline 4 & 80 & 140 & 5 & 6.56 & 8.88 & $2.51 \pm 0.06$ & 2.35 & $93.1 \pm 0.8$ & 91.6 & $18.7 \pm 1.7$ & 20.0 & $32.6 \pm 15.8$ & 35.0 \\
\hline 5 & 60 & 110 & 3 & 11.63 & 14.70 & $3.43 \pm 0.11$ & 3.26 & $90.7 \pm 0.8$ & 90.1 & $24.1 \pm 2.1$ & 23.8 & $31.8 \pm 1.5$ & 39.9 \\
\hline 6 & 60 & 110 & 7 & 14.06 & 16.77 & $4.06 \pm 0.19$ & 3.33 & $90.9 \pm 0.5$ & 89.9 & $19.6 \pm 4.2$ & 20.9 & $34.7 \pm 5.5$ & 37.1 \\
\hline 7 & 60 & 140 & 3 & 18.55 & 22.09 & $3.99 \pm 0.10$ & 4.22 & $86.6 \pm 4.1$ & 87.6 & $20.2 \pm 1.4$ & 20.2 & $46.9 \pm 3.9$ & 34.7 \\
\hline 8 & 60 & 140 & 7 & 26.09 & 24.16 & $4.24 \pm 0.04$ & 4.29 & $85.5 \pm 2.8$ & 87.4 & $18.7 \pm 0.7$ & 17.3 & $32.8 \pm 0.4$ & 31.9 \\
\hline 9 & 40 & 125 & 3 & 12.38 & 11.33 & $2.30 \pm 0.06$ & 2.26 & $86.8 \pm 1.9$ & 86.9 & $18.3 \pm 0.6$ & 18.5 & $52.5 \pm 5.3$ & 45.4 \\
\hline 10 & 80 & 125 & 3 & 12.52 & 10.41 & $3.08 \pm 0.11$ & 2.94 & $91.8 \pm 1.0$ & 92.3 & $22.4 \pm 1.2$ & 21.3 & $28.3 \pm 2.0$ & 27.6 \\
\hline 11 & 40 & 125 & 7 & 10.30 & 13.41 & $1.62 \pm 0.09$ & 2.33 & $86.7 \pm 1.3$ & 86.6 & $16.3 \pm 0.8$ & 15.6 & $49.0 \pm 1.7$ & 42.5 \\
\hline 12 & 80 & 125 & 7 & 12.93 & 12.48 & $3.16 \pm 0.10$ & 3.01 & $91.9 \pm 0.6$ & 92.1 & $18.8 \pm 2.8$ & 18.4 & $24.1 \pm 7.1$ & 24.8 \\
\hline 13 & 60 & 125 & 5 & 18.76 & 19.43 & $3.12 \pm 0.17$ & 3.77 & $89.5 \pm 1.4$ & 88.8 & $21.7 \pm 0.7$ & 20.5 & $43.4 \pm 2.4$ & 35.9 \\
\hline 14 & 60 & 125 & 5 & 20.50 & 19.43 & $3.91 \pm 0.14$ & 3.77 & $89.7 \pm 1.6$ & 88.8 & $19.4 \pm 0.1$ & 20.5 & $36.7 \pm 2.9$ & 35.9 \\
\hline 15 & 60 & 125 & 5 & 26.42 & 19.43 & $3.67 \pm 0.07$ & 3.77 & $88.5 \pm 1.6$ & 88.8 & $20.0 \pm 0.5$ & 20.5 & $38.7 \pm 5.7$ & 35.9 \\
\hline
\end{tabular}

759 These mathematical models produced by response surface methodology were used to predict the yield and values of each antioxidant

760 property for variation of independent variables. The prediction values were very close to the experimental results which proved the

761 adequacy of the models. 
Table S.3. Analysis of variance (ANOVA) of the fitted second-order polynomial models for all antioxidant properties

\begin{tabular}{|c|c|c|c|c|c|}
\hline & $\begin{array}{c}\text { Sum of } \\
\text { squares }\end{array}$ & DF & $\begin{array}{c}\text { Mean } \\
\text { square }\end{array}$ & $F$-value & $p$-value \\
\hline \multicolumn{6}{|l|}{ Yield $^{\mathrm{a}}$} \\
\hline Model & 0.0487544 & 5 & 0.00975 & 8.0803 & 0.0038 \\
\hline Error & 0.0108608 & 9 & 0.001207 & & \\
\hline Lack of Fit & 0.0076358 & 7 & 0.001091 & 0.6765 & 0.7086 \\
\hline Pure error & 0.003225 & 2 & 0.001612 & & \\
\hline Total & 0.070476 & 23 & & & \\
\hline \multicolumn{6}{|c|}{ Total Phenolic Content ${ }^{b}$} \\
\hline Model & 12.563619 & 5 & 2.51272 & 10.0777 & 0.0017 \\
\hline Error & 2.244021 & 9 & 0.24934 & & \\
\hline Lack of Fit & 1.9159548 & 7 & 0.273708 & 1.6686 & 0.4249 \\
\hline Pure error & 0.3280667 & 2 & 0.164033 & & \\
\hline Total & 17.051662 & 23 & & & \\
\hline \multicolumn{6}{|l|}{ DPPH $^{\mathrm{c}}$} \\
\hline Model & 75.295548 & 5 & 15.0591 & 10.1737 & 0.0017 \\
\hline Error & 13.321786 & 9 & 1.4802 & & \\
\hline Lack of Fit & 12.495119 & 7 & 1.78502 & 4.3186 & 0.2009 \\
\hline Pure error & 0.826667 & 2 & 0.41333 & & \\
\hline Total & 101.93912 & 23 & & & \\
\hline \multicolumn{6}{|l|}{$\mathbf{A B T S}^{\mathrm{d}}$} \\
\hline Model & 90.6013 & 5 & 18.1203 & 14.4987 & 0.0004 \\
\hline Error & 11.24804 & 9 & 1.2498 & & \\
\hline Lack of Fit & 8.401369 & 7 & 1.2002 & 0.8432 & 0.6399 \\
\hline Pure error & 2.846667 & 2 & 1.42333 & & \\
\hline Total & 113.09738 & 23 & & & \\
\hline \multicolumn{6}{|c|}{ Iron Chelating Ability } \\
\hline Model & 1227.3038 & 5 & 245.463 & 9.1196 & 0.0025 \\
\hline Error & 242.2436 & 9 & 26.9160 & & \\
\hline Lack of Fit & 218.58357 & 7 & 31.2262 & 2.6396 & 0.3021 \\
\hline Pure error & 23.66 & 2 & 11.8300 & & \\
\hline Total & 1711.791 & 23 & & & \\
\hline
\end{tabular}

764

765

766

767

768
a. $\mathrm{R}^{2}$ : 0.817818; mean: 0.154193 ; adj $\mathrm{R}^{2}: 0.716606$

b. $\mathrm{R}^{2}: 0.848455$; mean: 3.168 ; adj $\mathrm{R}^{2}: 0.764264$

c. $R^{2}: 0.849671$; mean: 89.14667 ; adj $R^{2}: 0.766154$

d. $\mathrm{R}^{2}$ : 0.889562; mean: 16.24; adj $\mathrm{R}^{2}$ : 0.828208

e. $R^{2}: 0.835159$; mean: 19.42667 ; adj $R^{2}: 0.74358$ 


\begin{tabular}{|c|c|c|c|c|c|c|c|c|c|c|c|c|c|c|}
\hline No. & $\begin{array}{c}\text { Ethanol } \\
\text { Concentration } \\
(\% v / v)\end{array}$ & $\mathrm{T}\left({ }^{\circ} \mathrm{C}\right)$ & $\begin{array}{l}\text { Time } \\
(\min )\end{array}$ & Yield & $\begin{array}{c}\text { TPC (g GAE } \\
\left.\quad(100 \mathrm{~g})^{-1}\right)\end{array}$ & $\begin{array}{c}\text { DPPH at } \\
0.5 \mathrm{mg} \mathrm{mL}^{-1} \\
(\% \\
\text { inhibition) } \\
\end{array}$ & $\begin{array}{c}\text { ABTS at } 0.5 \\
\text { mg mL }^{-1}(\% \\
\text { inhibition) }\end{array}$ & $\begin{array}{c}\mathrm{Fe}^{2+} \\
\text { Chelating } \\
\text { Ability at } \\
1.5 \mathrm{mg} \\
\mathrm{mL}^{-1}(\%) \\
\end{array}$ & Desirability & $\begin{array}{c}\text { Yield } \\
\text { Desirability }\end{array}$ & $\begin{array}{c}\text { TPC } \\
\text { Desirability }\end{array}$ & $\begin{array}{c}\text { DPPH } \\
\text { Desirability }\end{array}$ & $\begin{array}{c}\text { ABTS } \\
\text { Desirability }\end{array}$ & $\begin{array}{c}\mathrm{Fe}^{2+} \\
\text { Chelating } \\
\text { Ability } \\
\text { Desirability } \\
\end{array}$ \\
\hline 1 & 47.18 & 130.92 & 6.17 & 0.203 & 3.580 & 86.59 & 16.71 & 36.48 & 0.5080 & 0.7004 & 0.6740 & 0.2180 & 0.5148 & 0.6387 \\
\hline 2 & 52.56 & 127.10 & 5.41 & 0.196 & 3.622 & 87.63 & 19.06 & 37.82 & 0.5773 & 0.6743 & 0.6831 & 0.3160 & 0.6625 & 0.6651 \\
\hline 3 & 72.74 & 138.77 & 3.29 & 0.149 & 3.295 & 90.13 & 21.32 & 35.43 & 0.6085 & 0.4972 & 0.6132 & 0.5652 & 0.7842 & 0.6176 \\
\hline 4 & 78.86 & 129.47 & 6.86 & 0.126 & 2.950 & 91.68 & 18.69 & 27.91 & 0.5426 & 0.4142 & 0.5411 & 0.7298 & 0.6408 & 0.4485 \\
\hline 5 & 77.87 & 128.29 & 5.56 & 0.129 & 3.071 & 91.59 & 19.72 & 28.58 & 0.5626 & 0.4242 & 0.5662 & 0.7206 & 0.6993 & 0.4657 \\
\hline 6 & 55.69 & 124.90 & 3.66 & 0.185 & 3.620 & 88.30 & 21.11 & 38.75 & 0.6129 & 0.6295 & 0.6826 & 0.3812 & 0.7733 & 0.6828 \\
\hline 7 & 51.78 & 136.57 & 6.69 & 0.241 & 4.195 & 86.52 & 16.35 & 32.56 & 0.5234 & 0.8478 & 0.8074 & 0.2105 & 0.4894 & 0.5574 \\
\hline 8 & 68.34 & 129.59 & 3.78 & 0.176 & 3.704 & 89.80 & 21.34 & 33.58 & 0.6324 & 0.5981 & 0.7008 & 0.5309 & 0.7850 & 0.5791 \\
\hline 9 & 48.35 & 133.51 & 5.12 & 0.214 & 3.832 & 86.50 & 17.23 & 35.43 & 0.5211 & 0.7428 & 0.7285 & 0.2088 & 0.5504 & 0.6176 \\
\hline 10 & 58.00 & 114.48 & 6.17 & 0.170 & 3.333 & 89.35 & 20.93 & 38.56 & 0.6174 & 0.5734 & 0.6213 & 0.4853 & 0.7637 & 0.6792 \\
\hline 11 & 70.81 & 116.14 & 3.50 & 0.160 & 3.670 & 91.06 & 22.22 & 29.80 & 0.6331 & 0.5377 & 0.6935 & 0.6630 & 0.8303 & 0.4954 \\
\hline 12 & 59.31 & 133.24 & 4.22 & 0.212 & 4.033 & 88.03 & 20.01 & 35.10 & 0.6150 & 0.7350 & 0.7722 & 0.3549 & 0.7151 & 0.6109 \\
\hline 13 & 58.80 & 126.24 & 3.54 & 0.190 & 3.770 & 88.59 & 21.34 & 37.18 & 0.6278 & 0.6508 & 0.7149 & 0.4091 & 0.7850 & 0.6526 \\
\hline 14 & 52.22 & 119.65 & 4.25 & 0.159 & 3.130 & 88.39 & 21.13 & 42.27 & 0.5870 & 0.5329 & 0.5784 & 0.3900 & 0.7744 & 0.7487 \\
\hline 15 & 71.19 & 135.00 & 4.12 & 0.165 & 3.503 & 89.98 & 20.84 & 33.84 & 0.6164 & 0.5551 & 0.6574 & 0.5495 & 0.7592 & 0.5845 \\
\hline 17 & 69.89 & 138.41 & 5.70 & 0.183 & 3.618 & 89.43 & 19.47 & 33.54 & 0.6078 & 0.6219 & 0.6823 & 0.4933 & 0.6854 & 0.5783 \\
\hline 18 & 58.66 & 137.18 & 4.68 & 0.226 & 4.193 & 87.57 & 19.07 & 33.97 & 0.5991 & 0.7908 & 0.8070 & 0.3106 & 0.6632 & 0.5873 \\
\hline 19 & 47.61 & 138.39 & 4.64 & 0.234 & 4.164 & 85.91 & 16.41 & 32.68 & 0.4886 & 0.8223 & 0.8007 & 0.1530 & 0.4937 & 0.5598 \\
\hline 20 & 79.86 & 134.74 & 5.55 & 0.102 & 2.601 & 91.75 & 19.59 & 31.58 & 0.5317 & 0.3303 & 0.4700 & 0.7383 & 0.6921 & 0.5358 \\
\hline 21 & 63.99 & 111.06 & 5.32 & 0.169 & 3.560 & 90.35 & 21.81 & 34.15 & 0.6405 & 0.5717 & 0.6699 & 0.5884 & 0.8095 & 0.5911 \\
\hline 22 & 41.65 & 123.74 & 6.58 & 0.136 & 2.405 & 86.93 & 16.65 & 43.32 & 0.4521 & 0.4476 & 0.4309 & 0.2496 & 0.5108 & 0.7680 \\
\hline 23 & 58.31 & 124.15 & 5.32 & 0.193 & 3.710 & 88.60 & 20.27 & 36.60 & 0.6170 & 0.6637 & 0.7022 & 0.4104 & 0.7292 & 0.6410 \\
\hline 24 & 61.66 & 136.65 & 6.81 & 0.227 & 4.130 & 87.98 & 18.04 & 32.57 & 0.5945 & 0.7962 & 0.7931 & 0.3503 & 0.6018 & 0.5576 \\
\hline 25 & 64.70 & 112.01 & 5.36 & 0.172 & 3.606 & 90.37 & 21.65 & 33.42 & 0.6401 & 0.5805 & 0.6797 & 0.5900 & 0.8013 & 0.5758 \\
\hline 26 & 62.97 & 115.01 & 3.50 & 0.166 & 3.562 & 90.04 & 22.79 & 36.21 & 0.6467 & 0.5584 & 0.6703 & 0.5550 & 0.8598 & 0.6333 \\
\hline 27 & 50.88 & 131.49 & 4.76 & 0.208 & 3.805 & 87.02 & 18.46 & 36.55 & 0.5578 & 0.7197 & 0.7227 & 0.2588 & 0.6271 & 0.6401 \\
\hline 28 & 71.64 & 119.38 & 6.71 & 0.175 & 3.680 & 90.82 & 19.66 & 27.71 & 0.6050 & 0.5925 & 0.6956 & 0.6378 & 0.6960 & 0.4433 \\
\hline 29 & 66.83 & 125.69 & 5.40 & 0.187 & 3.770 & 89.72 & 20.43 & 32.54 & 0.6281 & 0.6379 & 0.7151 & 0.5219 & 0.7375 & 0.5568 \\
\hline 30 & 54.78 & 128.05 & 4.53 & 0.199 & 3.757 & 87.85 & 19.89 & 37.34 & 0.5979 & 0.6844 & 0.7121 & 0.3374 & 0.7084 & 0.6557 \\
\hline 31 & 79.23 & 119.55 & 5.40 & 0.131 & 3.272 & 92.24 & 19.66 & 23.27 & 0.5397 & 0.4311 & 0.6084 & 0.7912 & 0.6958 & 0.3171 \\
\hline 32 & 77.13 & 118.19 & 5.39 & 0.145 & 3.453 & 91.91 & 19.99 & 24.14 & 0.5649 & 0.4809 & 0.6468 & 0.7550 & 0.7142 & 0.3431 \\
\hline 33 & 54.16 & 114.36 & 5.47 & 0.153 & 3.013 & 89.02 & 21.29 & 42.29 & 0.5953 & 0.5092 & 0.5541 & 0.4519 & 0.7826 & 0.7491 \\
\hline 34 & 52.65 & 127.54 & 6.69 & 0.205 & 3.675 & 87.52 & 18.07 & 36.68 & 0.5665 & 0.7077 & 0.6946 & 0.3059 & 0.6040 & 0.6426 \\
\hline
\end{tabular}




\begin{tabular}{|c|c|c|c|c|c|c|c|c|c|c|c|c|c|c|}
\hline No. & $\begin{array}{c}\text { Ethanol } \\
\text { Concentration } \\
(\% v / v)\end{array}$ & $\mathrm{T}\left({ }^{\circ} \mathrm{C}\right)$ & $\begin{array}{l}\text { Time } \\
(\min )\end{array}$ & Yield & $\begin{array}{c}\text { TPC (g GAE } \\
\quad\left(100 \mathrm{~g}^{-1}\right)\end{array}$ & $\begin{array}{c}\text { DPPH at } \\
0.5 \mathrm{mg} \mathrm{mL}^{-1} \\
(\% \\
\text { inhibition) }\end{array}$ & $\begin{array}{c}\mathrm{ABTS} \text { at } 0.5 \\
\mathrm{mg} \mathrm{mL}^{-1}(\% \\
\text { inhibition) }\end{array}$ & $\begin{array}{c}\mathrm{Fe}^{2+} \\
\text { Chelating } \\
\text { Ability at } \\
1.5 \mathrm{mg} \\
\mathrm{mL}^{-1}(\%) \\
\end{array}$ & Desirability & $\begin{array}{c}\text { Yield } \\
\text { Desirability }\end{array}$ & $\begin{array}{c}\text { TPC } \\
\text { Desirability }\end{array}$ & $\begin{array}{c}\text { DPPH } \\
\text { Desirability }\end{array}$ & $\begin{array}{c}\text { ABTS } \\
\text { Desirability }\end{array}$ & $\begin{array}{c}\mathrm{Fe}^{2+} \\
\text { Chelating } \\
\text { Ability } \\
\text { Desirability }\end{array}$ \\
\hline 35 & 73.31 & 134.08 & 3.22 & 0.146 & 3.312 & 90.51 & 21.54 & 33.93 & 0.6099 & 0.4848 & 0.6169 & 0.6047 & 0.7955 & 0.5864 \\
\hline 36 & 46.79 & 131.12 & 3.12 & 0.187 & 3.516 & 86.70 & 18.79 & 38.59 & 0.5312 & 0.6380 & 0.6603 & 0.2284 & 0.6467 & 0.6798 \\
\hline 37 & 69.72 & 114.86 & 5.59 & 0.173 & 3.721 & 90.85 & 20.87 & 28.95 & 0.6252 & 0.5854 & 0.7045 & 0.6411 & 0.7608 & 0.4749 \\
\hline 38 & 40.16 & 136.07 & 3.64 & 0.191 & 3.460 & 85.45 & 15.30 & 34.56 & 0.4065 & 0.6539 & 0.6484 & 0.1090 & 0.4005 & 0.5998 \\
\hline 39 & 56.74 & 113.69 & 5.03 & 0.158 & 3.188 & 89.36 & 21.83 & 40.66 & 0.6154 & 0.5282 & 0.5907 & 0.4855 & 0.8102 & 0.7190 \\
\hline 40 & 58.25 & 121.35 & 3.28 & 0.175 & 3.564 & 88.95 & 22.12 & 38.76 & 0.6305 & 0.5928 & 0.6707 & 0.4448 & 0.8251 & 0.6831 \\
\hline 41 & 43.69 & 122.98 & 5.85 & 0.141 & 2.567 & 87.21 & 17.85 & 43.59 & 0.4862 & 0.4659 & 0.4631 & 0.2761 & 0.5899 & 0.7728 \\
\hline 42 & 56.39 & 114.98 & 4.92 & 0.160 & 3.218 & 89.21 & 21.71 & 40.63 & 0.6140 & 0.5371 & 0.5970 & 0.4710 & 0.8044 & 0.7185 \\
\hline 43 & 71.59 & 114.02 & 6.82 & 0.175 & 3.741 & 91.11 & 19.82 & 26.22 & 0.6035 & 0.5944 & 0.7087 & 0.6691 & 0.7048 & 0.4029 \\
\hline 44 & 56.65 & 128.21 & 6.95 & 0.213 & 3.862 & 87.94 & 18.36 & 35.00 & 0.5896 & 0.7406 & 0.7350 & 0.3459 & 0.6215 & 0.6087 \\
\hline 45 & 63.78 & 129.15 & 4.60 & 0.196 & 3.867 & 89.02 & 20.61 & 34.34 & 0.6303 & 0.6723 & 0.7361 & 0.4522 & 0.7470 & 0.5952 \\
\hline 46 & 42.14 & 126.28 & 5.31 & 0.148 & 2.693 & 86.73 & 17.09 & 41.85 & 0.4671 & 0.4928 & 0.4885 & 0.2304 & 0.5407 & 0.7410 \\
\hline 47 & 52.36 & 126.08 & 3.60 & 0.182 & 3.518 & 87.80 & 20.52 & 39.66 & 0.5892 & 0.6206 & 0.6608 & 0.3332 & 0.7422 & 0.7002 \\
\hline 48 & 46.79 & 131.12 & 6.54 & 0.205 & 3.576 & 86.51 & 16.30 & 36.14 & 0.4981 & 0.7068 & 0.6731 & 0.2101 & 0.4856 & 0.6319 \\
\hline 49 & 46.03 & 110.93 & 4.31 & 0.082 & 1.788 & 88.84 & 22.03 & 52.13 & 0.4844 & 0.2597 & 0.3112 & 0.4336 & 0.8206 & 0.9277 \\
\hline 50 & 41.25 & 132.84 & 5.96 & 0.188 & 3.267 & 85.82 & 14.78 & 35.84 & 0.4149 & 0.6411 & 0.6074 & 0.1441 & 0.3503 & 0.6258 \\
\hline 51 & 52.49 & 140.00 & 7.00 & 0.256 & 4.420 & 86.25 & 15.70 & 30.78 & 0.5007 & 0.9092 & 0.8564 & 0.1857 & 0.4368 & 0.5179 \\
\hline
\end{tabular}



number 43 had highest desirability and could be considered as the second potential solution.

Mixture plot uses greyscale to show top potential solutions across all evaluated weight objectives combinations. Horizontal axis of this plot is the weight of TPC with a scale of zero to one because the sum of weigh of TPC, DPPH, and metal chelating is one. Vertical axis of the graph is the number assigned for each set of condition as shown in Table S.4. Darkest colour on the plot shows highest desirability for the selected weight of criteria set. This mixture plot was produced with no emphasize in metal chelating (weight $=0$ ). For maximum value of TPC without focusing on other parameters, weight value of one for TPC and zero for DPPH was selected. Solution set number 51 gave highest desirability and thus this set was chosen as the first potential solution. While more weight was put to DPPH (DPPH weight value of 0.4 and TPC weight value of 0.6 ), solution set

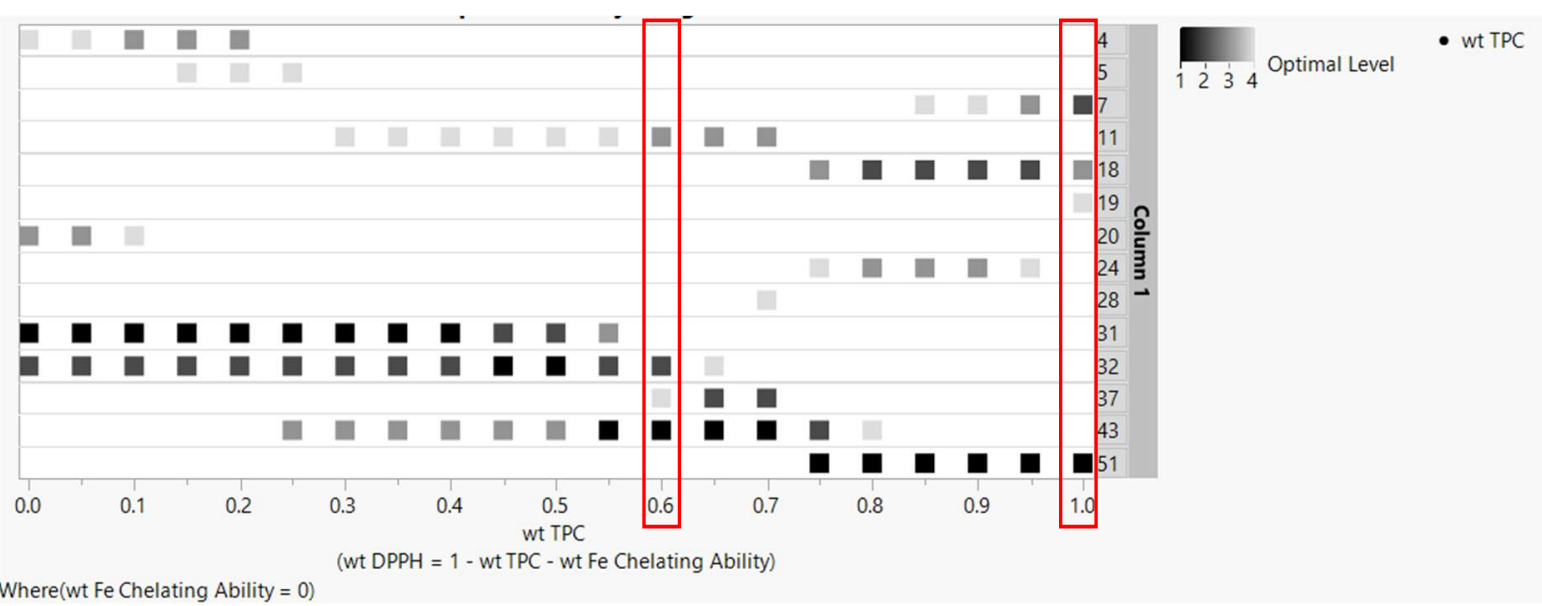

Fig. S.1. Mixture plot for weight value of metal chelating $=0$ 785 


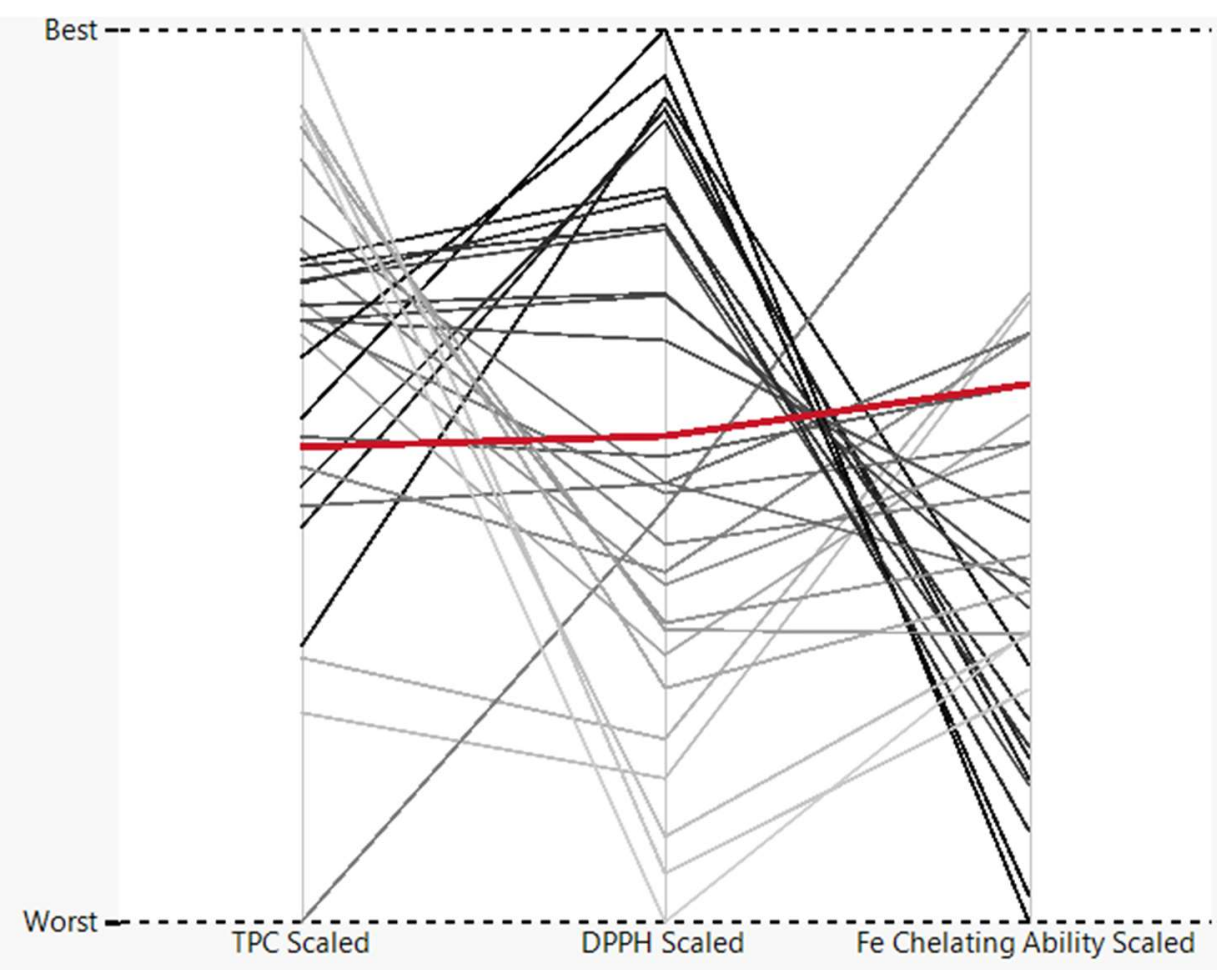

Fig. S.2. Parallel plot for all set of solutions

788

789 Parallel plot visually illustrates the trade-offs of one solution over another in terms of the scaled 790 criteria values. Best values of each criterion are on the top of the plot. Flatter lines in the graph 791 indicate less trade-off between the criteria. This plot shows that high values of TPC always had a 792 trade-off of low DPPH values. Contrarily, high values of DPPH had a trade-off of low metal 793 chelating activity. The best set of solution from this graph was indicated with the flattest gradients 794 of line (red line) and hence this set was chosen as the third potential solution. 


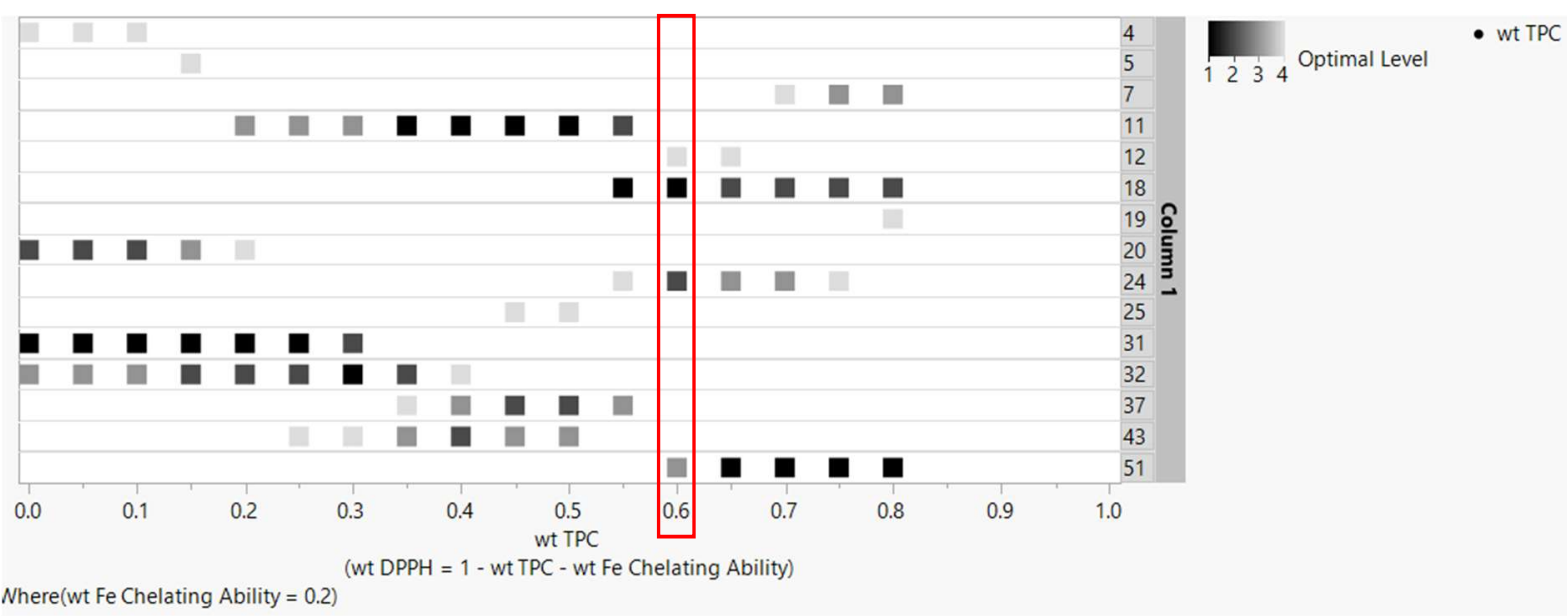

Fig. S.3. Mixture plot for weight value of metal chelating $=0.2$

802 Mixture plot uses greyscale to show top potential solutions across all evaluated weight objectives combinations. Horizontal axis of this plot is the weight of TPC with a scale of zero to one because

804 the sum of weigh of TPC, DPPH, and metal chelating is one. Vertical axis of the graph is the number assigned for each set of condition as shown in Table S.4. Darkest colour on the plot shows

806 highest desirability for the selected weight of criteria set. As metal chelating ability had different 807 profile than the other parameters which was shown in the parallel plot, this parameter was included 808 in a mixture plot with a weight of 0.2 . In this case, weight of DPPH was set on 0.2 and weight of 809 TPC was on 0.6 . The best desirability value for this condition was achieved by solution set number 81018 which was selected as the fourth potential solution. 